\title{
The importance of vertical velocity variability for estimates of the indirect aerosol effects
}

\author{
R. E. L. West ${ }^{1, *}$, P. Stier ${ }^{1}$, A. Jones ${ }^{2}$, C. E. Johnson ${ }^{2}$, G. W. Mann ${ }^{3}$, N. Bellouin ${ }^{2,{ }^{* *}}$, D. G. Partridge ${ }^{1}$, and Z. Kipling ${ }^{1}$ \\ ${ }^{1}$ Department of Physics, University of Oxford, Oxford, UK \\ ${ }^{2}$ Met Office Hadley Centre, Exeter, UK \\ ${ }^{3}$ National Centre for Atmospheric Science, University of Leeds, UK \\ * now at: Department for Environment, Food \& Rural Affairs, London, UK \\ *** now at: Department of Meteorology, University of Reading, Reading, UK
}

Correspondence to: P. Stier (philip.stier@physics.ox.ac.uk)

Received: 2 September 2013 - Published in Atmos. Chem. Phys. Discuss.: 17 October 2013

Revised: 13 April 2014 - Accepted: 28 April 2014 - Published: 26 June 2014

\begin{abstract}
The activation of aerosols to form cloud droplets is dependent upon vertical velocities whose local variability is not typically resolved at the GCM grid scale. Consequently, it is necessary to represent the subgrid-scale variability of vertical velocity in the calculation of cloud droplet number concentration.

This study uses the UK Chemistry and Aerosols community model (UKCA) within the Hadley Centre Global Environmental Model (HadGEM3), coupled for the first time to an explicit aerosol activation parameterisation, and hence known as UKCA-Activate. We explore the range of uncertainty in estimates of the indirect aerosol effects attributable to the choice of parameterisation of the subgrid-scale variability of vertical velocity in HadGEM-UKCA. Results of simulations demonstrate that the use of a characteristic vertical velocity cannot replicate results derived with a distribution of vertical velocities, and is to be discouraged in GCMs.

This study focuses on the effect of the variance $\left(\sigma_{\mathrm{w}}^{2}\right)$ of a Gaussian pdf (probability density function) of vertical velocity. Fixed values of $\sigma_{\mathrm{w}}$ (spanning the range measured in situ by nine flight campaigns found in the literature) and a configuration in which $\sigma_{\mathrm{w}}$ depends on turbulent kinetic energy are tested. Results from the mid-range fixed $\sigma_{\mathrm{w}}$ and TKE-based configurations both compare well with observed vertical velocity distributions and cloud droplet number concentrations.

The radiative flux perturbation due to the total effects of anthropogenic aerosol is estimated at $-1.9 \mathrm{~W} \mathrm{~m}^{-2}$ with $\sigma_{\mathrm{w}}=0.1 \mathrm{~m} \mathrm{~s}^{-1},-2.1 \mathrm{Wm}^{-2}$ with $\sigma_{\mathrm{w}}$ derived from TKE, $-2.25 \mathrm{~W} \mathrm{~m}^{-2}$ with $\sigma_{\mathrm{w}}=0.4 \mathrm{~m} \mathrm{~s}^{-1}$, and $-2.3 \mathrm{Wm}^{-2}$ with
\end{abstract}

$\sigma_{\mathrm{w}}=0.7 \mathrm{~m} \mathrm{~s}^{-1}$. The breadth of this range is $0.4 \mathrm{Wm}^{-2}$, which is comparable to a substantial fraction of the total diversity of current aerosol forcing estimates. Reducing the uncertainty in the parameterisation of $\sigma_{\mathrm{w}}$ would therefore be an important step towards reducing the uncertainty in estimates of the indirect aerosol effects.

Detailed examination of regional radiative flux perturbations reveals that aerosol microphysics can be responsible for some climate-relevant radiative effects, highlighting the importance of including microphysical aerosol processes in GCMs.

\section{Introduction}

The indirect effects of anthropogenic aerosols - through their interactions with clouds - are currently one of the most uncertain perturbations to the radiative energy balance at the top of the atmosphere (Forster et al., 2007). A crucial link between aerosol and cloud is that aerosols can act as cloud condensation nuclei $(\mathrm{CCN})$ in a process known as aerosol activation (Köhler, 1936). This microphysical process must be parameterised if the large-scale effects are to be represented in a general circulation model (GCM), and several parameterisations have been developed, evaluated and implemented in GCMs in the last decade (see Ghan et al., 2011).

The activation of aerosol to form cloud droplets is fundamentally dependent on the ambient supersaturation, which is strongly influenced by adiabatic cooling due to the vertical 
velocity of the rising air. Typically, the large-scale vertical velocities resolved at the GCM grid scale are small, and it is the unresolved subgrid-scale fluctuations which give rise to the updraughts associated with cloud formation. It is therefore necessary to account for this subgrid-scale variability if aerosol activation is to be represented meaningfully in a GCM.

In local Köhler-theory-based aerosol activation parameterisations (e.g. Abdul-Razzak et al., 1998; Nenes and Seinfeld, 2003; Ming et al., 2006; Shipway and Abel, 2010), the number of activated aerosols is predicted as a function of aerosol properties (size, number and composition), $a_{i}(i=$ $1 \ldots n)$, vertical velocity, $w$, temperature, $T$, and pressure, $p$, such that it can be expressed as $N_{\mathrm{a}}\left(a_{1}, \ldots, a_{n}, T, p, w\right)$. The average number of activated aerosols within a grid box is denoted as $\overline{N_{\mathrm{a}}}$. Such parameterisations are typically based upon adiabatic parcel model theory and have different levels of complexity.

The problem of representing subgrid-scale vertical velocity has been addressed in current GCMs by two distinct approaches. In the probability density function (pdf)-based approach, it is assumed that the probability density function of vertical velocity within each grid box has an explicit shape, $f(w)$, assumed continuous (Chuang et al., 1997; Ghan et al., 1997). The grid box parameterisation is thus determined by calculating the expected value of the local parameterisation over each grid box:

$\overline{N_{\mathrm{a}}}=\frac{\int_{0}^{\infty} N_{\mathrm{a}}\left(a_{1}, \ldots, a_{n}, T, p, w\right) f(w) \mathrm{d} w}{\int_{0}^{\infty} f(w) \mathrm{d} w}$.

Since aerosol activation does not occur in regions of downdraught, integration is only carried out for $w>0$.

By contrast, in the characteristic approach, it is assumed that the grid-box parameterisation can be obtained by simply substituting a characteristic vertical velocity, $w^{*}$, into the local parameterisation:

$\overline{N_{\mathrm{a}}}=N_{\mathrm{a}}\left(a_{1}, \ldots, a_{n}, T, p, w^{*}\right)$.

(An obvious motivation for this simplification is the reduction in computational expense by eliminating the integration required by the pdf-based approach at every timestep.) The method by which this average number of activated aerosols, $\overline{N_{\mathrm{a}}}$ (calculated by either method), is then related to the gridbox mean in-cloud droplet number concentration, $N_{\mathrm{d}}$, is dictated by whether the droplet number is treated prognostically or diagnostically by the particular cloud scheme available within the host GCM.

The paper is divided into four sections. Following the introduction in Sect. 1, Sect. 2 provides a brief overview of the host GCM and a description of the newly implemented mechanistic aerosol activation scheme within it. Section 2 also contains a description of the model configurations used to assess the model sensitivity to $\sigma_{\mathrm{w}}$, the standard deviation of a Gaussian distribution of vertical velocities. Section 3 contains the results of this experiment, and presents the impacts of different vertical velocity configurations on cloud droplet number concentration (CDNC) and liquid water path. The model is evaluated against in situ measurements of CCN, CDNC and vertical velocity statistics in Sect. 3.3. Results of radiative flux perturbation experiments to estimate the radiative effects of aerosols in each of the vertical velocity configurations are given in Sect. 3.4. These results also highlight some interesting effects due to aerosol microphysics. Finally, conclusions are drawn in Sect. 4. The remainder of this introduction provides a review of the characteristic and pdf-based approaches to the representation of vertical velocity variability, based on the Appendix to Golaz et al. (2011).

\subsection{Characteristic vertical velocity}

The first attempts to use model-derived vertical velocity in calculations of $N_{\mathrm{d}}$ relied upon the estimation of $w^{*}$, a single "characteristic" value of $w$ for each grid box e.g. Lohmann et al. (1999) used $w^{*}=\bar{w}+c \sqrt{\mathrm{TKE}}$, where $\bar{w}$ is the largescale grid-box mean vertical velocity, TKE the turbulent kinetic energy and $c$ an empirically derived factor. This approach was adopted by Takemura et al. (2005) and Goto et al. (2008), and adapted by Lohmann (2002) and Ming et al. (2007). An alternative approach, taken by Morrison and Gettelman (2008) and Gettelman et al. (2008), was to derive $w^{*}$ directly from the eddy diffusivity, $K$, and a constant characteristic mixing length, $l_{\mathrm{c}}=30 \mathrm{~m}$, via $w^{*}=$ $\max \left(\frac{K}{l_{c}}, 0.1\right) \mathrm{ms}^{-1}$. Wang and Penner (2009) use an amalgamation of both the Lohmann et al. (1999) and Morrison and Gettelman (2008) formulations. However, with increasing computing power, this method has been largely superseded by the pdf-based approach.

Interest in the concept of characteristic updraught has been recently rekindled in the literature (Morales and Nenes, 2010), but Sect. 3.2.4 of this study highlights the limitations of this approach, showing the results of applying the analytical expressions derived by Morales and Nenes (2010) over the full range of aerosol conditions simulated by a GCM.

\subsection{Pdf-based approaches to subgrid-scale variability}

Currently, a prevalent choice of representation of the subgrid variability of vertical velocity is the pdf, and most models that use this approach assume a Gaussian distribution of vertical velocities across the grid box, with mean $\bar{w}$ and standard deviation $\sigma_{\mathrm{w}}$ :

$f(w)=\frac{1}{\sqrt{2 \pi} \sigma_{\mathrm{w}}} \exp \left[-\left(\frac{(w-\bar{w})^{2}}{2 \sigma_{\mathrm{w}}^{2}}\right)\right]$.

Typically, $\bar{w}$ is taken to be the large-scale grid-box mean vertical velocity. Initially, fixed values of standard deviation were applied at all grid points (e.g. Chuang et al. (1997) used $\sigma_{\mathrm{w}}=0.5 \mathrm{~m} \mathrm{~s}^{-1}$, based on aircraft observations of stratocumulus cloud off the coast of California). In subsequent 
studies, $\sigma_{\mathrm{w}}$ became more commonly related to some measure of turbulence within the model. As discussed by Ghan et al. (1997), many processes can produce subgrid-scale variability in vertical velocity, but Ghan et al. (1997) assume that all subgrid-scale variability is due to turbulence; $\sigma_{\mathrm{w}}$ was diagnosed from the turbulent kinetic energy (if predicted by the host GCM, e.g. Eq. 6) or related to the eddy diffusivity by $\sigma_{\mathrm{w}}=\max \left(\frac{\sqrt{2 \pi} K}{\Delta z}, 0.1\right) \mathrm{ms}^{-1}$, where $\Delta z$ is grid-box height. The lower limit of $\sigma_{\mathrm{w}}=0.1 \mathrm{~ms}^{-1}$ is imposed because turbulence driven by radiative cooling at the cloud top is poorly resolved above the planetary boundary layer in GCMs with coarse vertical resolution $>100$ m (Ghan et al., 1997). In subsequent studies, this lower limit was raised to $\sigma_{\mathrm{w}}=0.2 \mathrm{~ms}^{-1}$ (Ghan et al., 2001a, b; Easter et al., 2004), and later to $\sigma_{\mathrm{w}}=0.3 \mathrm{~m} \mathrm{~s}^{-1}$ (Storelvmo et al., 2006). In the most recent modelling study that falls into this category, a much higher minimum value of $\sigma_{\mathrm{w}}=0.7 \mathrm{~m} \mathrm{~s}^{-1}$ was used in the reference case and found to occur $98 \%$ of the time (Golaz et al., 2011); $0.7 \mathrm{~m} \mathrm{~s}^{-1}$ is well above the average recorded $\sigma_{\mathrm{w}}$ across the flight campaigns through stratiform cloud considered in Sect. 2.4 of the present study and therefore applying such a high, fixed value in $98 \%$ of cases is surprising. Hoose et al. (2010) provide a summary of different formulations for $\sigma_{\mathrm{w}}$ and $w^{*}$ used in a variety of global models. They compare the behaviour of four parameterisations within the CAM-Oslo global aerosol-climate model (Storelvmo et al., 2006; Hoose et al., 2009) with observations and large eddy simulations from different flight campaigns. This work suggests that more widespread evaluation of simulated values of $\sigma_{\mathrm{w}}$ would be useful, and that caution should be exercised in the use of such lower limits on $\sigma_{\mathrm{w}}$.

The functional form of $f(w)$ may vary depending on cloud regime, boundary layer type and diurnal cycle (amongst other factors), and the processes governing this shape are far from understood and hence difficult to parameterise. Observations show that a Gaussian distribution may be a reasonable approximation for marine stratocumulus cloud (Peng et al., 2005). However, the subgrid variability of vertical velocity in other cloud regimes may be better approximated by other forms of $f(w)$. In situ observations from intensive aircraft campaigns, as well as longer-term statistics from permanent ground-based remote-sensing stations, in different regimes show that variance, skewness and kurtosis of vertical velocity distributions vary not only between different cloud types (Zhu and Zuidema, 2009), but also between clouds of the same type (Moyer and Young, 1991), and even within the vertical profile of a single cloud (Ghate et al., 2010). Hogan et al. (2009) presented ground-based measurements of negative skewness of vertical velocity associated with clouddriven mixing and showed that the sign of the skewness can vary within the same column below the cloud deck when under the influence of both surface-based and cloud-driven turbulence. This makes general parameterisation for use at the grid scale in GCMs particularly challenging.
Nevertheless, ongoing developments are underway to improve on the basic, initial approximation of a Gaussian pdf. Larson et al. (2002) used a combination of aircraft data and large eddy simulations (LES) to show that a double (binomial) Gaussian pdf provides the best representation of subgrid-scale variability in boundary layer cloud, out of five families of analytical pdfs tested, when compared to observed distributions from stratocumulus, cumulus and clear boundary layers measured during two flight campaigns (Albrecht et al., 1988, 1995). Following on from this, a turbulence cloud parameterisation based on the double Gaussian pdf has been developed (Golaz et al., 2002, 2007) and has recently been extended to the prediction of cloud droplet number in the single-column version of the GFDL GCM (Guo et al., 2010). This approach has recently been implemented in two separate GCMs (Guo et al., 2013; Bogenschutz et al., 2013).

An alternative approach may be to use a nested modelling framework, in which a LES or cloud-resolving model could be directly activated by GCMs in the most important boundary layer cloud-forming regions (Zhu et al., 2010). Currently, this approach is in the early development stages, but with potential increases in computational power in the future, it may prove to be useful.

In this study, we use a Gaussian pdf of vertical velocities and focus on exploring the effects of using a range of fixed values of $\sigma_{\mathrm{w}}$, as well as an experiment in which $\sigma_{\mathrm{w}}$ is derived from the model turbulent kinetic energy. Currently, measurements of vertical velocity statistics are so geographically and temporally sparse that even if a more complex functional form of $f(w)$ were deployed, its usefulness could only be informed by a very limited set of measurements. It would be difficult to evaluate whether it constituted a global improvement compared to observations, other than in the very limited temporal and spatial regime of such observations. For this reason, the added complexity of higher moments of $f(w)$ is not yet justifiable in a GCM, and this work will focus on the first and second moments alone, that is, the mean and standard deviation. A more extensive, co-ordinated measurement effort, in conjunction with further LES studies, would be required to make further progress on the parameterisation of subgrid vertical velocity variability for GCMs.

There are clearly many uncertain aspects to calculating the radiative effects of aerosols. This study resolves to build on previous work and reduce this uncertainty by focusing on one parameter in particular, the standard deviation of a Gaussian pdf of vertical velocity, $\sigma_{\mathrm{w}}$. The aim of the study is to quantify what effect, if any, changing this parameter ultimately has on estimates of the indirect aerosol radiative effects. 


\section{Microphysical aerosol-cloud interactions in HadGEM-UKCA}

\subsection{Modelling framework overview}

The modelling framework used for this study is the composition-climate model, HadGEM-UKCA (http://www. ukca.ac.uk), which extends the Hadley Centre Global Environmental Model (HadGEM) with an aerosol-chemistry sub-model coupled to the general circulation model radiation scheme. We run HadGEM-UKCA version 7.3 in atmosphereonly configuration, whereby sea-surface temperatures and sea-ice extent are prescribed as seasonally varying fields, with the atmosphere model being a developmental version of the third generation of HadGEM (Hewitt et al., 2011).

All integrations of the model described in this paper utilise this configuration on a staggered Arakawa C-grid (Arakawa and Lamb, 1977) with a resolution of $\mathrm{N} 96\left(1.25^{\circ}\right.$ latitude $\times 1.875^{\circ}$ longitude). A staggered Charney-Phillips grid is used in the vertical with 38 levels extending up to $39 \mathrm{~km}$. The dynamical timestep corresponding to this resolution is $30 \mathrm{~min}$.

Coupled within the climate model, UKCA uses components of HadGEM3 for the large-scale advection, convective transport, and boundary layer mixing of its chemical tracers. Large-scale transport is based on the new dynamical core implemented in HadGEM by Davies et al. (2005). Advection is semi-Lagrangian with conservative and monotone treatment of tracers. Convective transport is treated according to the mass-flux scheme of Gregory and Rowntree (1990) and is applicable to moist convection of all types (shallow, deep, and mid-level) in addition to dry convection. For boundary layer mixing, UKCA uses the boundary layer turbulent mixing scheme of Lock et al. (2000) which includes a representation of non-local mixing in unstable layers and an explicit entrainment parameterisation.

HadGEM-UKCA is available with either tropospheric chemistry (Telford et al., 2010; O'Connor et al., 2014) or stratospheric chemistry (Morgenstern et al., 2009). A whole-atmosphere chemistry scheme that combines both approaches is also currently in development. Simulations presented in this study use the standard tropospheric chemistry scheme (StdTrop) with aerosol chemistry to couple it to the GLOMAP-mode aerosol microphysics module (Mann et al., 2010), as in the studies by Bellouin et al. (2013) and Kipling et al. (2013). The StdTrop chemistry simulates the $\mathrm{O}_{\mathrm{x}}, \mathrm{HO}_{\mathrm{x}}$ and $\mathrm{NO}_{\mathrm{x}}$ chemical cycles and the oxidation of $\mathrm{CO}$, ethane and propane with eight emitted species, 102 gas-phase reactions, 27 photolysis reactions and interactive wet and dry deposition schemes.

The aerosol chemistry extension to StdTrop additionally treats the degradation of sulfur dioxide $\left(\mathrm{SO}_{2}\right)$, dimethyl sulfide (DMS) and a monoterpene tracer. In addition, two tracers are used to represent species required for the processes of aerosol nucleation and condensation within GLOMAP- mode: sulfuric acid $\left(\mathrm{H}_{2} \mathrm{SO}_{4}\right)$ produced from the oxidation of $\mathrm{SO}_{2}$ with the hydroxyl radical $(\mathrm{OH})$, and a secondary organic species representing the condensable species from monoterpene oxidation. The oxidation of $\mathrm{SO}_{2}$ within clouds is also included, with aqueous sulfate produced via reactions with dissolved hydrogen peroxide $\left(\mathrm{H}_{2} \mathrm{O}_{2}\right)$ and ozone $\left(\mathrm{O}_{3}\right)$.

Aerosol modelling in UKCA is accomplished with a modal version of the Global Model of Aerosol Processes (GLOMAP) (Spracklen, 2005; Spracklen et al., 2008), known as GLOMAP-mode (Mann et al., 2010). This is a twomoment pseudo-modal scheme which carries both aerosol number concentration and component mass as prognostic tracers. The aerosol dynamics framework follows that of the M7 model (Vignati et al., 2004). Details of the aerosol modes and the permitted component species within each mode are given in Table 1.

Although dust is a core component resolved within GLOMAP-mode (e.g. Mann et al., 2010), when the scheme is used within HadGEM-UKCA, dust is transported via the existing six-bin scheme (Woodward, 2001). (This aspect of UKCA is still under development, as is the inclusion of ammonium nitrate as an aerosol component.)

Within GLOMAP-mode, aerosol processes are represented following the approach of the original sectional aerosol model, GLOMAP-bin (Spracklen, 2005; Spracklen et al., 2008; Mann et al., 2012). This includes nucleation of sulfuric acid, condensation, coagulation and cloud processing. Direct size-resolved emissions of sulfate, black carbon, organic carbon and sea salt particles are included, and secondary aerosol production from sulfur and terpene oxidation is taken into account. The oxidation of mono-terpene by $\mathrm{O}_{3}$, $\mathrm{OH}$ and $\mathrm{NO}_{3}$ is included explicitly, but the condensable product yield is fixed at $0.13 \%$. Hygroscopic growth of all modes and ageing of insoluble modes by condensation or coagulation with soluble components are included. Finally, aerosol removal by both dry and wet deposition (sedimentation and scavenging) are also included. Full details of these processes are given by Mann et al. (2010).

\subsection{Interactions between aerosols, chemistry and radiation}

The HadGEM-UKCA framework allows the online simulated composition (both aerosols and chemistry) to be fully coupled with the radiation scheme of the general circulation model. Radiatively active trace gases simulated by the chemistry scheme affect radiative fluxes. The direct interaction of aerosols with radiation, by scattering and absorption of radiative fluxes, is modelled explicitly (Bellouin, 2010), based on the dynamically varying aerosol properties simulated by GLOMAP-mode (Mann et al., 2010). In the simulations presented here, both the direct and indirect radiative effects of the simulated aerosol are applied directly to the atmosphere model, but the model can also be run in double-call 
Table 1. Configuration of the GLOMAP-mode aerosol scheme, with component species: sulfate (SO4), sea salt (SS), black carbon (BC), organic carbon (OC), and dust (DU). Note that dust is not currently available for use in UKCA. $\bar{D}$ is the geometric mean diameter and $\sigma_{\mathrm{g}}$ the geometric standard deviation defining each log-normal mode.

\begin{tabular}{lcclr}
\hline Mode & Soluble? & Diameter range (microns) & Composition & $\sigma_{\mathrm{g}}$ \\
\hline Nucleation & Yes & $\bar{D}<0.01$ & SO4, OC & 1.59 \\
Aitken & Yes & $0.01<\bar{D}<0.1$ & SO4, BC, OC & 1.59 \\
Accumulation & Yes & $0.1<\bar{D}<1$ & SO4, BC, OC, SS, [DU] & 1.59 \\
Coarse & Yes & $\bar{D}>1$ & SO4, BC, OC, SS, [DU] & 2.0 \\
Aitken & No & $0.01<\bar{D}<0.1$ & BC, OC & 1.59 \\
Accumulation & No & $0.1<\bar{D}<1$ & [DU] & 1.59 \\
Coarse & No & $\bar{D}>1$ & [DU] & 2.0 \\
\hline
\end{tabular}

configuration to enable clean forcing experiments and process studies (e.g. Bellouin et al., 2013).

The refractive index of each aerosol mode varies with the changing internal composition of the mode, and is calculated interactively by volume averaging. Mie look-up tables are then used to obtain the aerosol optical properties (i.e. the specific scattering and absorption coefficients and the asymmetry parameter, which describes the angular dependence of scattering). These allow the direct interactions of aerosol with both longwave and shortwave radiation to be modelled.

\subsubsection{Indirect aerosol effects}

The focus of this study is on the indirect radiative effects of aerosol, via its interaction with cloud. Aerosol activation is critically dependent on the number, size and composition of aerosols, as well as the local supersaturation of water vapour. The new UKCA activation scheme described here explicitly represents these factors by coupling the dynamically evolving two-moment-modal aerosol scheme GLOMAP-mode to a Köhler-theory-based aerosol activation parameterisation (Abdul-Razzak and Ghan, 2000) to diagnose cloud droplet number concentration.

The indirect aerosol effects themselves are simulated following a standard method (e.g. see Jones et al., 2001). HadGEM3 uses the PC2 (prognostic cloud fraction and condensation) cloud scheme (Wilson et al., 2008), in which cloud droplet number concentration $\left(N_{\mathrm{d}}\right)$ is a purely diagnostic quantity, derived directly from the expected number of aerosols that are available to activate at each time step $\left(\overline{N_{\mathrm{a}}}\right)$. Cloud droplet number concentration is used in the calculation of liquid cloud droplet effective radius $\left(r_{\mathrm{e}}\right)$, which allows the cloud albedo effect to be modelled. In the Edwards-Slingo radiation code in HadGEM3, this effective radius is parameterised following Martin et al. (1994):

$r_{\mathrm{e}}=\left(\frac{3}{4 \pi} \frac{\rho_{\mathrm{air}} q_{\mathrm{c}}}{\rho_{\mathrm{w}} k N_{\mathrm{d}}}\right)^{1 / 3}$,

where $q_{\mathrm{c}}$ is the cloud liquid water content $\left(\mathrm{kg} \mathrm{kg}^{-1}\right)$ and $\rho_{\text {air }}$ and $\rho_{\mathrm{w}}$ the densities of air and liquid water. The value of $k$ represents the cloud droplet spectral dispersion, and is set to empirically derived values of 0.67 over land and 0.8 over ocean (Martin et al., 1994).

For large-scale precipitation, the rate of increase of rain water by autoconversion of cloud droplets to precipitation, $R_{\text {auto }}$, is parameterised as

$R_{\text {auto }}=\frac{0.104 g E_{\mathrm{c}} \rho_{\text {air }}^{\frac{4}{3}}}{\mu \rho_{\mathrm{w}}^{\frac{1}{3}}} \frac{q_{\mathrm{c}}^{\frac{7}{3}}}{N_{\mathrm{d}}^{\frac{1}{3}}}$,

where $g$ is the acceleration due to gravity and $\mu$ is the dynamic viscosity of air. $E_{\mathrm{c}}$ is the collision/collection efficiency of cloud droplets (assumed to be 0.55, Tripoli and Cotton, 1980). Within the scheme, autoconversion occurs when the liquid water content, $q_{\mathrm{c}}$, is above a certain threshold. Once in progress, the process of autoconversion is numerically prevented from decreasing the liquid water content below this threshold value. $R_{\text {auto }}$ is also dependent on $N_{\mathrm{d}}$ (and hence aerosol), as shown in Eq. (5). Autoconversion is allowed to proceed when the concentration of cloud droplets with radius greater than $20 \mu \mathrm{m}$ exceeds $1000 \mathrm{~m}^{-3}$, found by assuming a Khrgian-Mazin modified gamma cloud droplet size distribution.

\subsection{Reference model configuration}

The model integrations in this study have been run for one year (with a discarded, three-month spin-up period preceding each run). Each simulation was run twice, once with pre-industrial (PI) and once with present-day (PD) aerosol emissions. Aerosol emissions for the years 1860 (PI) and 2000 (PD) are taken from the Coupled Model Intercomparison Project Phase 5 (CMIP5) emissions data set (Lamarque et al., 2010), provided to support modelling activities for the IPCC fifth assessment report. For biomass burning emissions, grass-fire emissions are added to the surface layer, and emissions from forest fires are assumed to be equally distributed between model levels two and twelve (approximately from $50 \mathrm{~m}$ up to $3 \mathrm{~km}$ ). Dimethyl sulfide (DMS) emissions are estimated from the interactive scheme in HadGEM3. 
Table 2. Definitions of vertical velocity pdfs in HadGEM-UKCA configurations.

\begin{tabular}{lc}
\hline Reference & Standard deviation $\left[\mathrm{m} \mathrm{s}^{-1}\right]$ \\
\hline sigw0.1 & $\sigma_{\mathrm{W}}=0.1$ \\
sigw0.4 & $\sigma_{\mathrm{W}}=0.4$ \\
sigw0.7 & $\sigma_{\mathrm{W}}=0.7$ \\
TKE_0.1 & $\sigma_{\mathrm{W}}=\max \left(\sqrt{\frac{2}{3} \mathrm{TKE}}, 0.1\right)$ \\
\hline
\end{tabular}

In the simulations performed for this study, HadGEMUKCA was run in a nudged configuration, that is, Newtonian relaxation was used to adjust the dynamical variables of horizontal wind and potential temperature in the free-running GCM towards time-varying fields of ERA-Interim data for the year 2008 (Telford et al., 2008, 2013).

\subsection{Representation of subgrid-scale vertical velocity variability}

Within HadGEM-UKCA, the subgrid variability of vertical velocity is represented using a Gaussian distribution of vertical velocities across the grid box, $f(w)$, with mean, $\bar{w}$, (taken to be the large-scale grid-box mean vertical velocity) and standard deviation, $\sigma_{\mathrm{w}}$.

To assess the effects of the choice of $\sigma_{\mathrm{w}}$ in the Gaussian distribution of vertical velocity, HadGEM-UKCA has been run in four different configurations, outlined in Table 2. In the first three configurations, sigw0.1, sigw0.4 and sigw0.7, fixed values of $\sigma_{\mathrm{w}}$ at $0.1,0.4$ and $0.7 \mathrm{~m} \mathrm{~s}^{-1}$ are applied universally.

These values have been established from a survey of published vertical velocity statistics and CDNC, measured in situ by flight campaigns. A range of such campaigns has been selected from the literature. A brief summary of the purpose and location of each campaign is given in Table 3. These flight campaigns all focused on marine boundary layer stratiform cloud. Detailed descriptions of each campaign, the aircraft flown, instrumentation onboard and discussions of the implications of the scientific findings can be found in the references listed in Table 3.

To establish a representative value of $\sigma_{\mathrm{w}}$, the mean of the values of $\sigma_{\mathrm{w}}$ tabulated in each study was taken, and the median was then taken of these mean values, giving $0.4 \mathrm{~m} \mathrm{~s}^{-1}$. The majority of measured values of $\sigma_{\mathrm{w}}$ in the set lie within the range $0.1<\sigma_{\mathrm{w}}<0.7 \mathrm{~m} \mathrm{~s}^{-1}$, and these two values - chosen to be equidistant from the median — are then broadly representative upper and lower bounds of $\sigma_{\mathrm{w}}$ within stratiform cloud.

In configuration TKE_0.1, $\sigma_{\mathrm{w}}$ is estimated from the modelled turbulent kinetic energy. Following the method of Ghan et al. (1997), it is assumed that all subgrid-scale variability in vertical velocity is due to turbulence. HadGEM3 uses the Lock et al. (2000) boundary layer turbulent mix- ing scheme. This scheme combines non-locally determined eddy-diffusivity profiles for turbulence driven by both surface fluxes and cloud-top processes (radiative and evaporative cooling), with an explicit parameterisation for the entrainment rate (derived by Lock, 1998).

The turbulent mixing scheme operates throughout the lowest $\sim 2.5 \mathrm{~km}$ of the model troposphere (vertical levels 1 to 11 inclusive), covering the planetary boundary layer and often the lower levels of the free atmosphere. Within these levels, turbulent kinetic energy (TKE) is diagnosed from the modelled eddy diffusivity profiles as

$\mathrm{TKE}=\left(\frac{K}{l}\right)^{2}$

where $K$ is the eddy diffusivity coefficient and $l$ the mixing length. Within the planetary boundary layer, $l$ is a combination of boundary layer depth and height above the surface, dependent on the type of boundary layer (Lock and Edwards, 2011; Lock et al., 2000). Above the planetary boundary layer but still within levels 1 to 11 , the model contains no physical way of calculating a mixing length in the free atmosphere, so a fixed value of $l=40 \mathrm{~m}$ is used to calculate TKE from Eq. (6).

Turbulent kinetic energy per unit mass can be defined as TKE $=\frac{1}{2}\left(\sigma_{\mathrm{u}}^{2}+\sigma_{\mathrm{v}}^{2}+\sigma_{\mathrm{w}}^{2}\right)$. Assuming isotropic turbulence (Ghan et al., 1997; Golaz et al., 2011), this can be approximated by TKE $=\frac{3}{2} \sigma_{\mathrm{w}}^{2}$, such that within the scope of the turbulent mixing scheme, $\sigma_{\mathrm{w}}$ can hence be diagnosed as

$\sigma_{\mathrm{w}}=\max \left(\sqrt{\frac{2}{3} \mathrm{TKE}}, \sigma_{\mathrm{w}}^{\min }\right) \mathrm{ms}^{-1}$.

In levels 12 to 38 , above the realm of the turbulent mixing scheme, neither $K$ nor $l$ are calculated, so turbulent kinetic energy is not diagnosed by the model, and $\sigma_{\mathrm{w}}$ must take on a fixed value, chosen here to be $\sigma_{\mathrm{w}}^{\min }=0.1 \mathrm{~m} \mathrm{~s}^{-1}$.

\section{Results}

\subsection{Evaluation of surface cloud condensation nuclei}

In order to evaluate simulated cloud-relevant aerosol, surface $\mathrm{CCN}$ concentrations were diagnosed from the model for each timestep at 38 distinct supersaturations $(S)$ corresponding to the most common values in a recent compilation of CCN measurements (Spracklen et al., 2011). These measurements comprise of 278 observations at 80 locations from 55 separate studies in the peer-reviewed literature. Measurements were made by independent research groups over the years 1971-2009, using a variety of instruments, with $S$ ranging from $0.02 \%$ to $1.5 \%$. The majority of observations are from surface sites (including several from ship-borne instruments) and we compare only to those in the lowest two kilometres. 
Table 3. Details of flight campaigns through marine stratiform clouds used for model evaluation.

\begin{tabular}{|c|c|c|c|c|c|c|}
\hline Campaign & Dates & Location & $\begin{array}{l}\text { Cloud } \\
\text { type }\end{array}$ & $\begin{array}{l}\text { No. } \\
\text { obs }\end{array}$ & Campaign focus & References \\
\hline NARE & $\begin{array}{l}\text { Aug to Sep } \\
1993\end{array}$ & $\begin{array}{l}\text { NW Atlantic, } \\
\text { Gulf of Maine } \\
\text { and Bay of } \\
\text { Fundy }\end{array}$ & St & 20 & $\begin{array}{l}\text { Indirect aerosol effects in } \\
\text { smooth-air, light-turbulence } \\
\text { conditions }\end{array}$ & $\begin{array}{l}\text { Leaitch et al. (1996); Peng } \\
\text { et al. (2005); Gultepe and Isaac } \\
\text { (1996) }\end{array}$ \\
\hline SOCEX & $\begin{array}{l}20 \text { Jan to } 9 \\
\text { Feb } 1995\end{array}$ & $\begin{array}{l}\text { Southern } \\
\text { Ocean, west of } \\
\text { Tasmania }\end{array}$ & $\mathrm{Sc}$ & 8 & $\begin{array}{l}\text { Cloud properties in unpolluted } \\
\text { region. No record of } \sigma_{\mathrm{w}} \text {. }\end{array}$ & Boers et al. (1998) \\
\hline ACE-1 & $\begin{array}{l}15 \mathrm{Nov} \\
\text { to } 14 \mathrm{Dec} \\
1995\end{array}$ & $\begin{array}{l}\text { Southern } \\
\text { Ocean, south of } \\
\text { Australia }\end{array}$ & $\mathrm{Sc}$ & 14 & $\begin{array}{l}\text { Summertime clouds in remote } \\
\text { region }\end{array}$ & $\begin{array}{l}\text { Yum et al. (1998); Bates et al. } \\
\text { (1998); Hudson et al. (1998) }\end{array}$ \\
\hline ACE-2 & Jul 1997 & $\begin{array}{l}\text { NE Atlantic, } \\
\text { near Canary } \\
\text { Islands }\end{array}$ & $\mathrm{Sc}$ & 8 & Indirect aerosol effects & $\begin{array}{l}\text { Guibert et al. (2003); } \\
\text { Pawlowska and Brenguier } \\
(2000)\end{array}$ \\
\hline CSTRIPE & Jul 2003 & $\begin{array}{l}\text { NE Pacific, off } \\
\text { California }\end{array}$ & $\mathrm{Sc}$ & 52 & Coastal Stratocumulus & Meskhidze et al. (2005) \\
\hline MASE-I & Jul 2005 & $\begin{array}{l}\text { NE Pacific, off } \\
\text { California }\end{array}$ & $\mathrm{Sc}$ & 9 & Aerosol-cloud relationships & Lu et al. (2007) \\
\hline CLOPAP & $\begin{array}{l}30 \text { Sep } \\
2005\end{array}$ & $\begin{array}{l}\text { Thames Estu- } \\
\text { ary and English } \\
\text { Channel }\end{array}$ & St, Sc & 4 & $\begin{array}{l}\text { Effect of urban aerosols on } \\
\text { cloud microphysics }\end{array}$ & Romakkaniemi et al. (2009) \\
\hline MASE-II & Jul 2007 & $\begin{array}{l}\text { NE Pacific, off } \\
\text { California }\end{array}$ & $\mathrm{Sc}$ & 11 & $\begin{array}{l}\text { Repeat of MASE-I with fo- } \\
\text { cus on ship tracks. For our } \\
\text { purposes, MASE-II observa- } \\
\text { tions are combined with those } \\
\text { of MASE-I and CSTRIPE } \\
\text { (NEPac-MASE-CSTRIPE) }\end{array}$ & Lu et al. (2009) \\
\hline $\begin{array}{l}\text { VOCALS- } \\
\text { REx }\end{array}$ & $\begin{array}{l}16 \text { Oct to } \\
15 \text { Nov } \\
2008\end{array}$ & $\begin{array}{l}\text { SE Pacific, off } \\
\text { Chile }\end{array}$ & $\mathrm{Sc}$ & 69 & $\begin{array}{l}\text { Structure of Sc-topped BL and } \\
\text { lower troposphere. For our pur- } \\
\text { poses, observations are split } \\
\text { into three longitude bins: } 70 \text { to } \\
75 \mathrm{~W} \text { (VOCALS-70-75), } 75 \text { to } \\
\text { 80W (VOCALS-75-80) and } 80 \\
\text { to } 85 \mathrm{~W} \text { (VOCALS-80-85). }\end{array}$ & Bretherton et al. (2010) \\
\hline
\end{tabular}

Figure 1 shows a scatter plot of measured versus modelled CCN number concentrations, matched by month, location and supersaturation. Measurements taken during observation periods lasting less than a month are plotted against the monthly mean modelled $\mathrm{CCN}$ number concentration at the closest value of $S$, at the nearest horizontal grid point. For cruise measurements spanning several grid boxes, the grid point closest to the mean of the range of latitude and longitude of the cruise is chosen. Measurements from longer observation periods are plotted against the average of the modelled CCN values over that period. Errors on CCN measurements are assumed to be $\pm 40 \%$ with a minimum absolute uncertainty of $20 \mathrm{~cm}^{-3}$ (Spracklen et al., 2011).

In all, $90 \%$ of points are within a factor of ten of the $1: 1$ line, and the linear Pearson correlation coefficient between the logarithms of the measured and modelled CCN concentrations is $r=0.592$. Modelled CCN tend to be biased low compared to the measurements, with a normalised mean bias of $-61.7 \%$, and this issue is under active investigation. The main deficiency is thought to be due to a low-bias in marine CCN. For example, in Fig. 1 there is a large cluster of points at measured $\mathrm{CCN} 50-200 \mathrm{~cm}^{-3}$ where the model is consistently low biased by a factor of two compared to the observations. These points are almost entirely for measurement locations in the marine boundary layer (MBL), where modelled CCN are known to be biased low in the current model. Future model releases will address this issue.

The visible group of outliers at measured $\mathrm{CCN}$ of order $1000 \mathrm{~cm}^{-3}$ corresponds to two studies in the Amazon region in late September and early October, and the model clearly underestimates the number of $\mathrm{CCN}$. This is likely due to uncertainties in the assumed size distribution for emitted biomass burning aerosol which has been shown to be an important source of uncertainty in aerosol microphysics simulations of global CCN (Lee et al., 2013). 


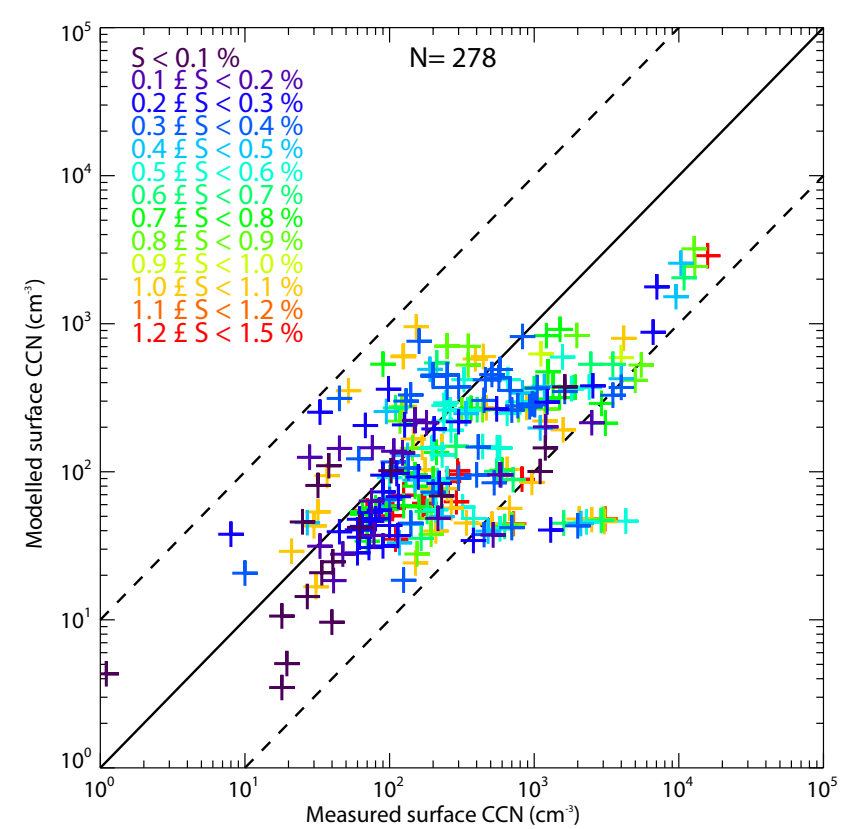

Figure 1. CCN measurements from 55 studies, versus co-located modelled monthly mean surface concentration of $\mathrm{CCN}$ at the same supersaturation and location. Points are coloured by supersaturation.

\subsection{Impacts of different vertical velocity configurations}

In this section, we examine how differences between each of the configurations of vertical velocity described in Sect. 2.4 affect simulated CDNC and liquid water path (LWP). Figures 2 and 3 illustrate how differences in choice of $\sigma_{\mathrm{w}}$ manifests in the annual mean fields of CDNC and LWP. Note that these simulations use present-day aerosols only.

\subsubsection{Cloud droplet number concentration}

In this paper, annual mean values of CDNC are not weighted by cloud fraction. Instead, a flag is used to identify "cloudy" grid boxes at each time step, and thus to produce in-cloud temporal and spatial averages of CDNC and other cloud properties (where "cloudy" grid boxes are defined as those in which both the cloud liquid water content and liquid cloud fraction exceed zero). While there are shortcomings to this choice, primarily that grid boxes with small and large cloud fractions are weighted equally in the time mean, it was chosen for more realistic comparisons with satellite observations and in situ measurements of CDNC, which are not weighted by cloud fraction. CDNC is presented both at liquid cloudtop level (Fig. 2) and at a typical cloud-base level $(720 \mathrm{~m}$, Fig. 8c and d) for illustration purposes and for comparison with satellite measurements and in situ observations respectively.

Figure 2a shows annual mean CDNC sampled at liquid cloud top in model configuration sigw0.4 (see Table 2).
The choice of $\sigma_{\mathrm{w}}$ can have a significant impact on CDNC, as shown in Fig. 2b, in which the difference in annual mean CDNC at cloud top between model configurations sigw0.7 and sigw 0.1 is on average $31.5 \mathrm{~cm}^{-3}$ and in excess of $100 \mathrm{~cm}^{-3}$ over many continental regions. The magnitude of the global mean relative difference is greatest in regions of high CCN concentration (e.g. over China) where increasing the width of the vertical velocity pdf allows activation of much smaller particles. Since the number distribution of aerosols in each mode is log-normal, decreasing the size of the smallest particle that activates can significantly increase the total number activated.

However, the increase in CDNC with increasing $\sigma_{\mathrm{w}}$ is only sub-linearly related to the increase in $\sigma_{\mathrm{w}}$, as illustrated in Fig. 2c. An increase of $\sigma_{\mathrm{w}}=0.1$ to $\sigma_{\mathrm{w}}=0.4 \mathrm{~m} \mathrm{~s}^{-1}$ leads to a global area-weighted mean increase in CDNC of $21.8 \mathrm{~cm}^{-3}$ but the magnitude of the increase is less than half as large $\left(9.67 \mathrm{~cm}^{-3}\right)$, when $\sigma_{\mathrm{w}}$ is increased by the same amount from 0.4 to $0.7 \mathrm{~m} \mathrm{~s}^{-1}$. Over land, where CCN are saturated, the effect is more pronounced. The non-linearity in this response is due to a levelling-out of the fraction of activation with increasing supersaturation ("fraction of activation" refers to the number of activated aerosols out of the total number of aerosols). Once the fraction of activation is close to unity, further increases in $\sigma_{\mathrm{w}}$ cease to have an effect.

\subsubsection{Liquid water path}

Figure 3a shows annual mean liquid water path in model configuration sigw0.4 (see Table 2). Broadly speaking, increasing $\sigma_{\mathrm{w}}$ corresponds to an increase of LWP, particularly over ocean, although the signal is noisy, due to differences in feedbacks between the model runs (shown in the difference between sigw0.1 and sigw0.7 in Fig. 3b).

As shown in Fig. 2b, an increase in $\sigma_{\mathrm{w}}$ can lead to an increase in $N_{\mathrm{d}}$, because the higher updraught velocities enable more of the smaller aerosols to activate, due to the increase in maximum supersaturation. Smaller droplets take longer to grow to raindrop size by the collision/coalescence process, thus decreasing the precipitation efficiency of the cloud and increasing the cloud liquid water content.

\subsubsection{TKE-derived $\sigma_{\mathrm{w}}$}

In configuration TKE_0.1, the standard deviation of the vertical velocity pdf is derived from the local TKE as described in Table 2. In order to see the regions where this dependency has the greatest impact, Fig. 4 shows the difference in $\sigma_{\mathrm{w}}$ and $N_{\mathrm{d}}$ between model configurations TKE_0.1 and sigw0.4.

At the most common level for cloud base $(720 \mathrm{~m})$, the most prominent regions where $\sigma_{\mathrm{w}}$ exceeds $0.4 \mathrm{~ms}^{-1}$ are the stratocumulus regions off the west coasts of North and South America, northern and southern Africa and Australia. It is interesting to see that at this level, TKE-derived $\sigma_{\mathrm{w}}$ 


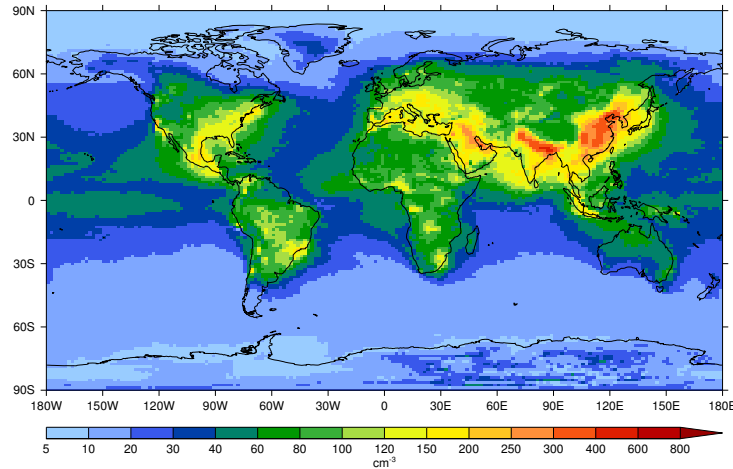

(a) $\mathrm{CDNC}$ at cloud top: sigw0.4

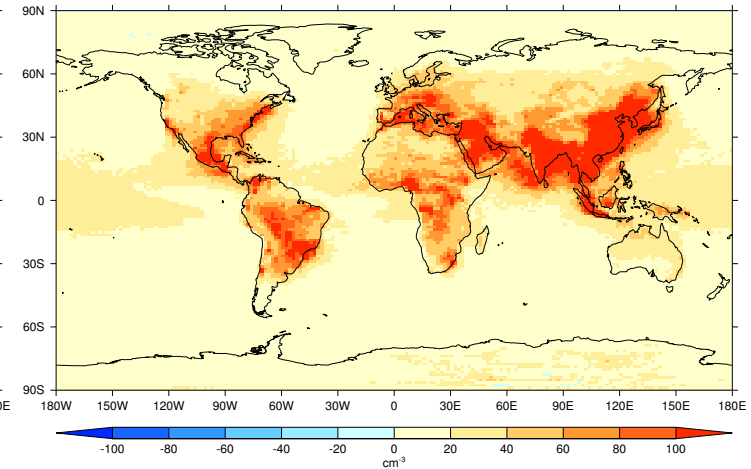

(b) Difference in CDNC: sigw0.7 - sigw0.1

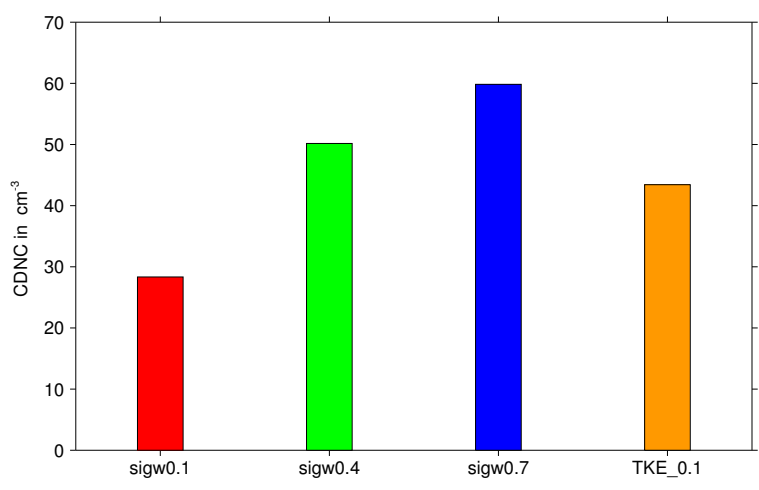

(c) Global mean CDNC

Figure 2. (a) Annual mean cloud droplet number concentration at cloud top in model configuration sigw0.4 (area-weighted mean, $\left.\mathrm{AWM}=50.17 \mathrm{~cm}^{-3}\right)$, (b) difference in annual mean CDNC at cloud top between model runs sigw0.7 and sigw0.1 $\left(\mathrm{AWM}=31.50 \mathrm{~cm}{ }^{-3}\right)$ and (c) global mean CDNC at cloud top for each model configuration. Note non-linear colour bar in (a).

makes significant departures from the reference case $\left(\sigma_{\mathrm{w}}=\right.$ $0.4 \mathrm{~m} \mathrm{~s}^{-1}$ ) in both positive and negative directions.

However, most interestingly, other than these rather small differences, comparing Fig. $4 \mathrm{a}$ and b demonstrates that $N_{\mathrm{d}}$ from TKE_0.1 is barely greater than $N_{\mathrm{d}}$ obtained in sigw 0.4 in any of the other regions where the TKE-derived $\sigma_{\mathrm{w}}$ exceeded $0.4 \mathrm{~m} \mathrm{~s}^{-1}$, such as the persistent stratocumulus region in the southeast Pacific. This indicates that the CDNC in such regions is limited by the low $\mathrm{CCN}$ concentration.

\subsubsection{Characteristic vertical velocity}

HadGEM-UKCA has been used to explore the form of characteristic vertical velocity proposed by Morales and Nenes (2010). This study defines the characteristic vertical velocity, $w^{*}$, to be the value of $w$ for which $N_{\mathrm{a}}\left(w^{*}\right)=\overline{N_{\mathrm{a}}}$. Essentially, an analytical formulation of $w^{*}$ is proposed, based on the Twomey (1959) approximation which assumes a power law dependence of the $\mathrm{CCN}$ spectrum (i.e. $N_{\mathrm{a}}=c S^{k}$ ). The characteristic updraught is expressed as $w^{*}=\lambda \sigma_{\mathrm{w}}$, and an analytical expression is derived to give $\lambda$ in terms of $k$ (the steepness of the CCN spectrum).
The values of $\lambda$ relevant to a GCM can be calculated by using a pdf of vertical velocities to calculate $\overline{N_{\mathrm{d}}}$ at each grid point within the GCM, but also diagnosing what the characteristic updraught would have been at each grid point to give the expected CDNC obtained with the pdf. $\lambda$ can then be calculated from the known (either prescribed or diagnosed) value of $\sigma_{\mathrm{w}}$.

Figure 5 shows the annual mean of $\lambda$ derived in this way from HadGEM-UKCA in configuration sigw0.4. Even in the annual mean, $\lambda$ is highly spatially variable, and takes on values from $\lambda=0.1$ to 0.8 with an area-weighted mean value of 0.5 . We note that this range extends considerably lower than the values that Morales and Nenes suggest might be appropriate $(\lambda=0.65$ derived using the Twomey expression for $N_{\mathrm{a}}$ or $\lambda=0.68$ derived from Fountoukis and Nenes, 2005). Given the variable spatial (and temporal, not shown) nature of $\lambda$ derived from the GCM with a full pdf, it seems inappropriate to assume that a fixed value of $\lambda$ would be suitable for use in a GCM.

Furthermore, box-model tests (not shown) indicate that when using a pdf, only 20 bins of $w$ are required over the range $0<w<4 \sigma_{\mathrm{w}}$ to calculate $\overline{N_{\mathrm{d}}}$ to within $2 \%$ of that 


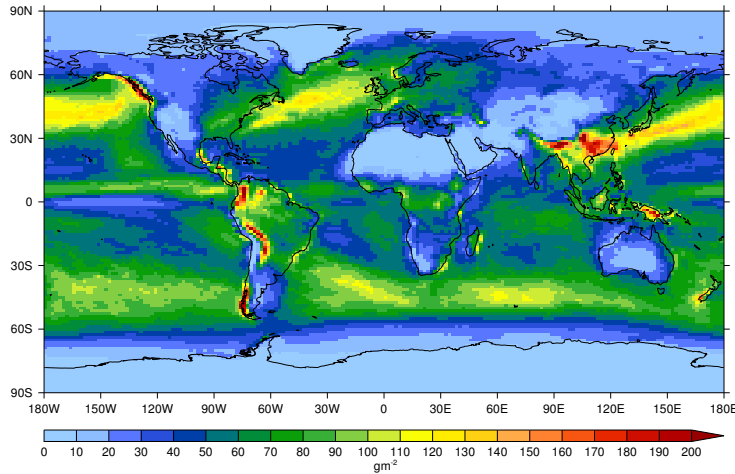

(a) Liquid water path: sigw0.4

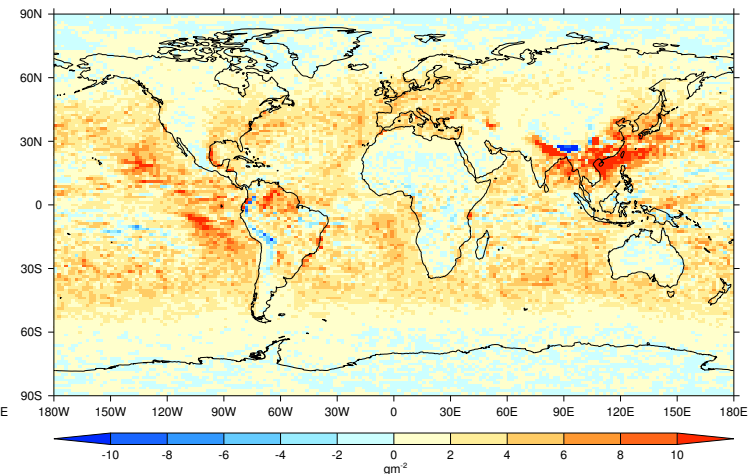

(b) Difference in LWP: sigw0.7 - sigw0.1

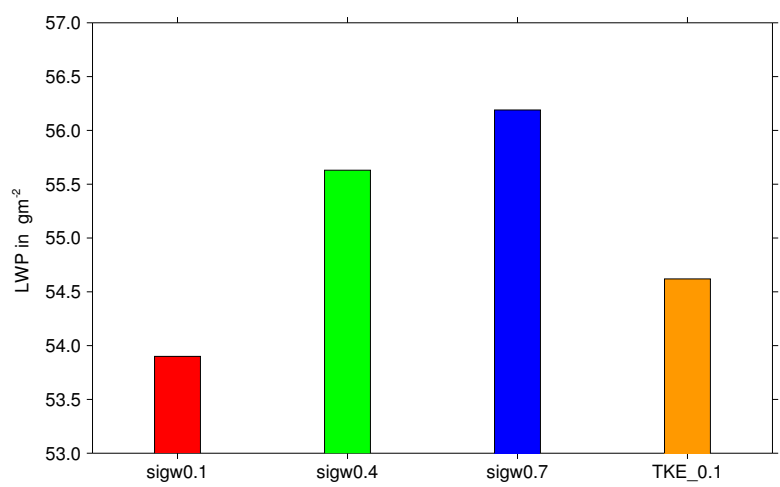

(c) Global mean LWP

Figure 3. (a) Annual mean liquid water path in model run sigw0.4 (AWM $=55.63 \mathrm{~g} \mathrm{~m}^{-2}$ ), (b) difference in annual mean LWP between model runs sigw0.7 and sigw0.1 (AWM $\left.=2.28 \mathrm{~g} \mathrm{~m}^{-2}\right)$, and (c) global mean LWP for each model configuration (note vertical axis shown from $53.0 \mathrm{~g} \mathrm{~m}^{-2}$ upwards).

obtained using 100000 bins over the range $0<w<10 \sigma_{\mathrm{w}}$ (for $0.1<\sigma_{\mathrm{w}}<2.0 \mathrm{~m} \mathrm{~s}^{-1}$ ) and thus the computational costs of the pdf-based approach need not be prohibitive. Finally, use of a characteristic updraught would seem to underestimate the potential effect of the non-linear relationship between $w^{*}$ and CDNC, and hence add unnecessary extra uncertainty to estimates of the indirect aerosol effects.

\subsection{Evaluation of CDNC and vertical velocity against in situ measurements}

High time-resolution output from each of the configurations of HadGEM-UKCA listed in Table 2, has been co-located in time and space with each of the flight campaigns listed in Table 3 as follows. (Full details of the flight campaigns and aircraft instrumentation may be obtained from the references in Table 3.)

\subsubsection{Time}

Model output was taken from the whole month of the simulation corresponding to the month of the mean date of the measurements (albeit with mismatched years), since flight cam- paigns had a typical duration of three to four weeks. Model diagnostics were output instantaneously every three hours, but only one of these three-hourly time slices was used per day for the appropriate month at each location, since campaigns typically made one flight per day (albeit sometimes sampling more than one cloud). For campaigns that published the time that each flight started, model output for each day of the month was sampled at the time slice closest to the mean flight start time. For campaigns that did not publish times of flights, the time slice closest to 12:00 LT (local time) was sampled, since most flights were made during daylight hours.

\subsubsection{Space}

The geographic extent of most of the flight campaigns was comparable in area to the horizontal model grid spacing $\left(1.875^{\circ} \times 1.25^{\circ}\right)$, so model output for each campaign was sampled for the grid box nearest to the mean longitude and latitude values of the flights recorded. For campaigns that did not publish latitude and longitude of each flight, these have been estimated from figures of flight paths, or from 


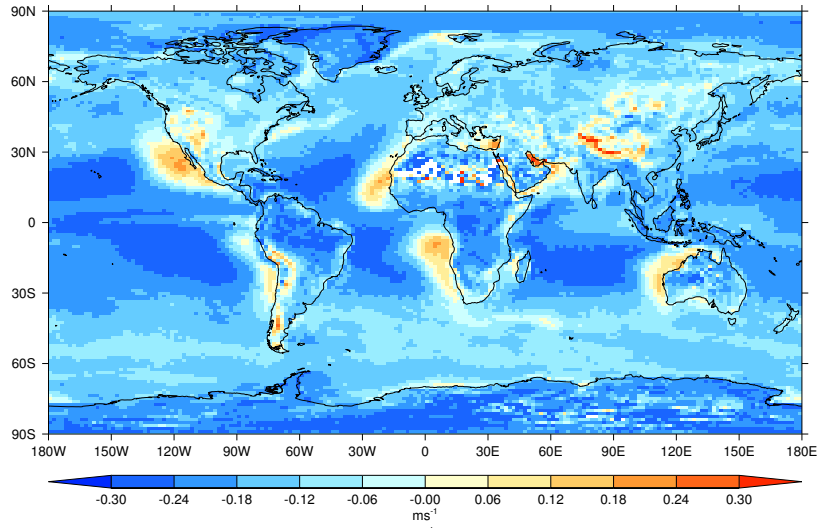

(a) Difference in $\sigma_{\mathrm{w}}$ : TKE_0.1 - sigw0.4

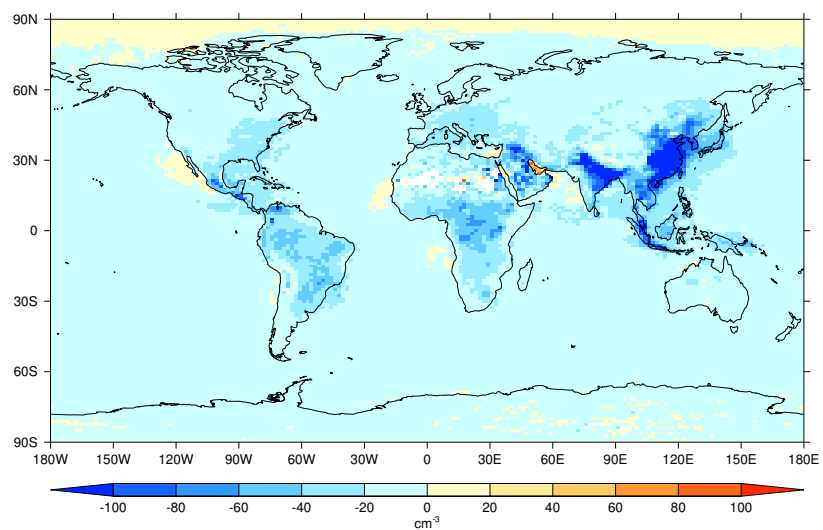

(b) Difference in CDNC: TKE_0.1 - sigw0.4

Figure 4. Annual mean in-cloud $\sigma_{\mathrm{w}}$ and CDNC at $720 \mathrm{~m}$. Panels show differences between model configuration TKE_0.1 with respect to sigw0.4 for (a) in-cloud $\sigma_{\mathrm{W}}\left(\mathrm{AWM}=-0.15 \mathrm{~ms}^{-1}\right)$ and (b) $\mathrm{CDNC}\left(\mathrm{AWM}=-12.53 \mathrm{~cm}^{-3}\right)$.

supplementary mission reports. The locations of these flight campaigns is shown in Fig. 6.

Most of the measurements considered in the database were taken at cloud base. In the case of multi-layer clouds, it is assumed that aircraft were flown through the lowest layer, since low-level clouds were the focus of most of the campaigns. Therefore, modelled in-cloud properties were sampled at the base of the lowest cloud in a column at that time step, that is, in the lowest "cloudy" grid box, where "cloudy" is defined as any grid box in which both liquid water content and liquid cloud fraction are greater than zero.

\subsubsection{Comparisons between model and observations}

In Fig. 7a the range, interquartile range and median value of CDNC and $\sigma_{\mathrm{w}}$ measured during each flight campaign listed in Table 3 are compared with the same statistics drawn from the co-located model data from each of the configurations listed in Table 2. For each campaign, observations are shown

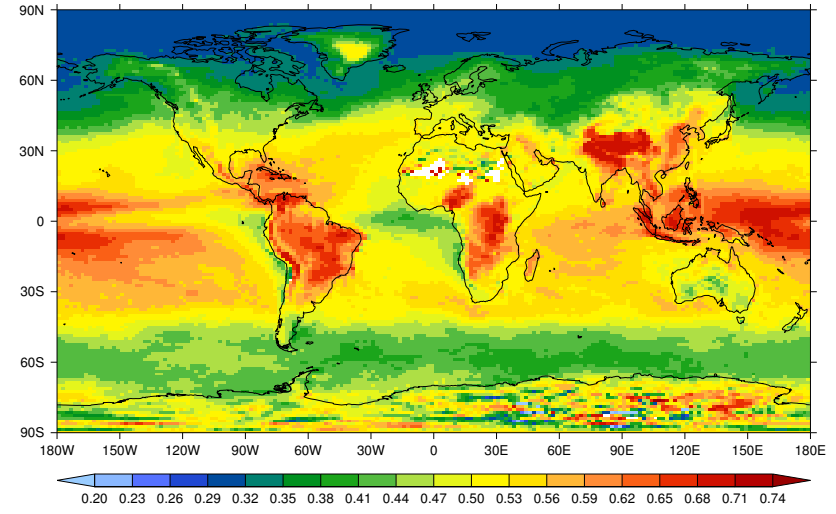

Figure 5. Annual mean in-cloud $\lambda$ calculated from $w^{*}=\lambda \sigma_{\mathrm{w}}$ from model configuration sigw0.4 at hybrid height of $720 \mathrm{~m}(\mathrm{AWM}=$ $0.51)$.

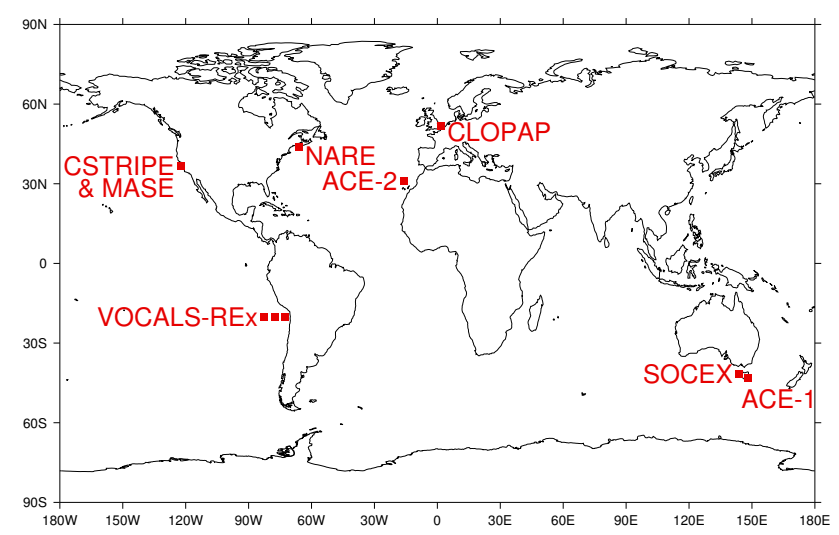

Figure 6. Map of flight campaign locations.

on the left of each group followed by distributions from each model configuration. In Fig. 7b, published observations of $\sigma_{\mathrm{w}}$ are plotted, followed by distributions from TKE_0.1 and appropriate fixed values of $\sigma_{\mathrm{w}}$ for experiments sigw0.1, sigw0.4, and sigw0.7.

Note that both phases of MASE (MASE I \& II) and CSTRIPE sampled the persistent stratocumulus cloud deck over the north-east Pacific, off the coast of Monterey, California, in July (albeit of different years), and these measurements were aggregated for our purposes and referred to as NEPac-MASE-CSTRIPE.

Model TKE_0.1 shows a good match to the observed median CDNC for NARE. For NARE, the interquartile range (IQR) of CDNC from TKE_0.1 is very similar to the observed IQR, although the median and 75th percentile of $\sigma_{\mathrm{w}}$ from TKE_0.1 are much higher than that observed. For CLOPAP, the 75th percentile of modelled $\sigma_{\mathrm{w}}$ also exceeds observations, although the median modelled $\sigma_{\mathrm{w}}$ is slightly lower than that observed. It is possible for these cases that an excess of $\sigma_{\mathrm{w}}$ may be compensated for by a lack of $\mathrm{CCN}$ at these points in the model. 


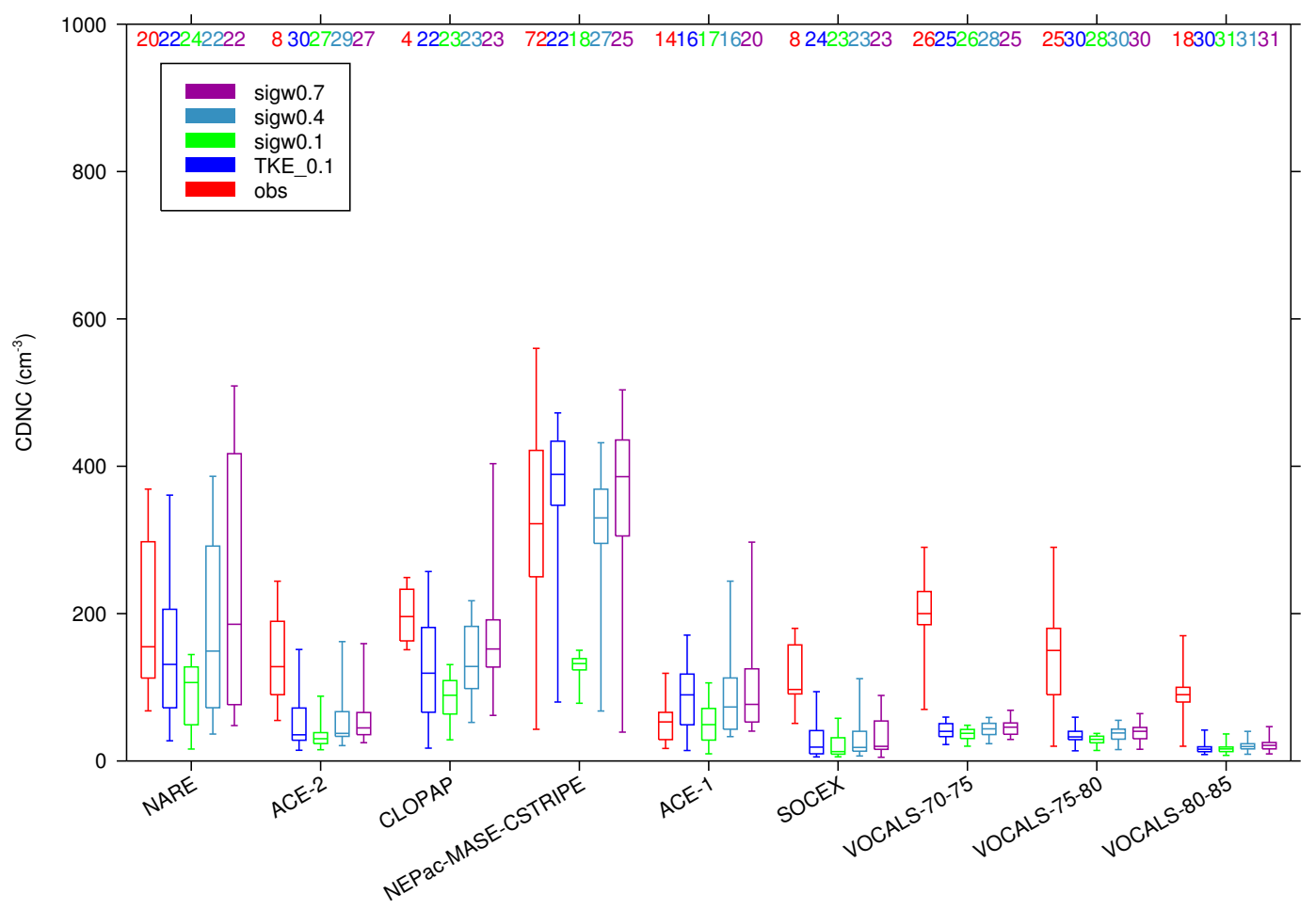

(a) CDNC distributions from observations and models

Figure 7a. Box-and-whisker plots showing minimum, 25th percentile, median, 75th percentile and maximum values of (a) CDNC and (b) $\sigma_{\mathrm{w}}$, from flight campaign observations (where reported) in red, and each model configuration (TKE_0.1 in blue, sigw0.1 in green; sigw0.4 in turquoise and sigw0.7 in purple) for marine stratiform flight campaigns. Sample size is given across the top of each figure.

CDNC are slightly overestimated by TKE_0.1 compared to observations for NEPac-MASE-CSTRIPE and ACE-1. For NEPac-MASE-CSTRIPE, it is clear from Fig. 7b that modelled $\sigma_{\mathrm{w}}$ is too high, since the modelled median far exceeds the median of the observations, and this excess in $\sigma_{\mathrm{w}}$ probably leads to some of the excess CDNC in Fig. 7a. That increasing $\sigma_{\mathrm{w}}$ can increase CDNC in this region is also evident from the different ranges of CDNC simulated by the three model runs with fixed $\sigma_{\mathrm{w}}$ (sigw0.1, sigw0.4 and sigw0.7). However, modelled CCN may also be too high in this region. For ACE-1, it is likely that an excess of modelled CCN is the strongest contributing factor to the excess of CDNC, since the median CDNC from model runs sigw0.4 and sigw0.7 exceeds the median observed CDNC (and is only just less in sigw0.1, for which the prescribed $\sigma_{\mathrm{w}}$ is far lower than the observed median of $\sigma_{\mathrm{w}}=0.5 \mathrm{~m} \mathrm{~s}^{-1}$ ).

CDNC are significantly underestimated by TKE_0.1 for SOCEX, ACE-2, and all three VOCALS cases, compared to observations. One reason for this is that the lowest cloudy model level can occur below the decoupled stratocumulus layer, in a region of low TKE. This leads to unrealistically low values of $\sigma_{\mathrm{w}}$ in some regions, particularly for SOCEX, VOCALS-80-85 and VOCALS-70-75. However, a lack of model CCN is also a significant factor, as discussed in Sect. 3.1. In the VOCALS cases it is clear that low model
$\mathrm{CCN}$ dominates the low $\sigma_{\mathrm{w}}$, since even when the modelled $\sigma_{\mathrm{w}}$ far exceeds that observed, the number of modelled CDNC is much less than that observed. (For instance, for VOCALS$70-75$, the number of CDNC modelled by sigw0.7, is much less than the number observed, even though the median observed $\sigma_{\mathrm{w}}=0.4 \mathrm{~m} \mathrm{~s}^{-1}$.) This lack of modelled CCN has been verified with profiles of $\mathrm{CCN}$ obtained along the $20^{\circ} \mathrm{S}$ transect of VOCALS-REx (not shown), in which the number concentration of $\mathrm{CCN}$ away from coastal sources has a value closer to $200 \mathrm{~cm}^{-3}$ at $S=0.4 \%$ (J. Snider, personal communication, 2011), compared to low values in the range 20 $50 \mathrm{~cm}^{-3}$ as simulated by the model. The lack of modelled $\mathrm{CCN}$ at this location in HadGEM-UKCA could simply be due to a difference between the prescribed aerosol emissions in this region (from the CMIP5 aerosol emissions inventory for the year 2000, Lamarque et al. (2010), compared to what actually happened locally during the VOCALS-REx campaign in 2008. However, it is likely that the low CCN bias in the marine boundary layer seen in Fig. 1 plays a significant role in this underestimation, and this issue is under active investigation.

Of course, $\mathrm{CCN}$ concentration and $\sigma_{\mathrm{w}}$ are not the only contributing factors to CDNC; aerosol hygroscopicity (composition), temperature and pressure will also play secondary 


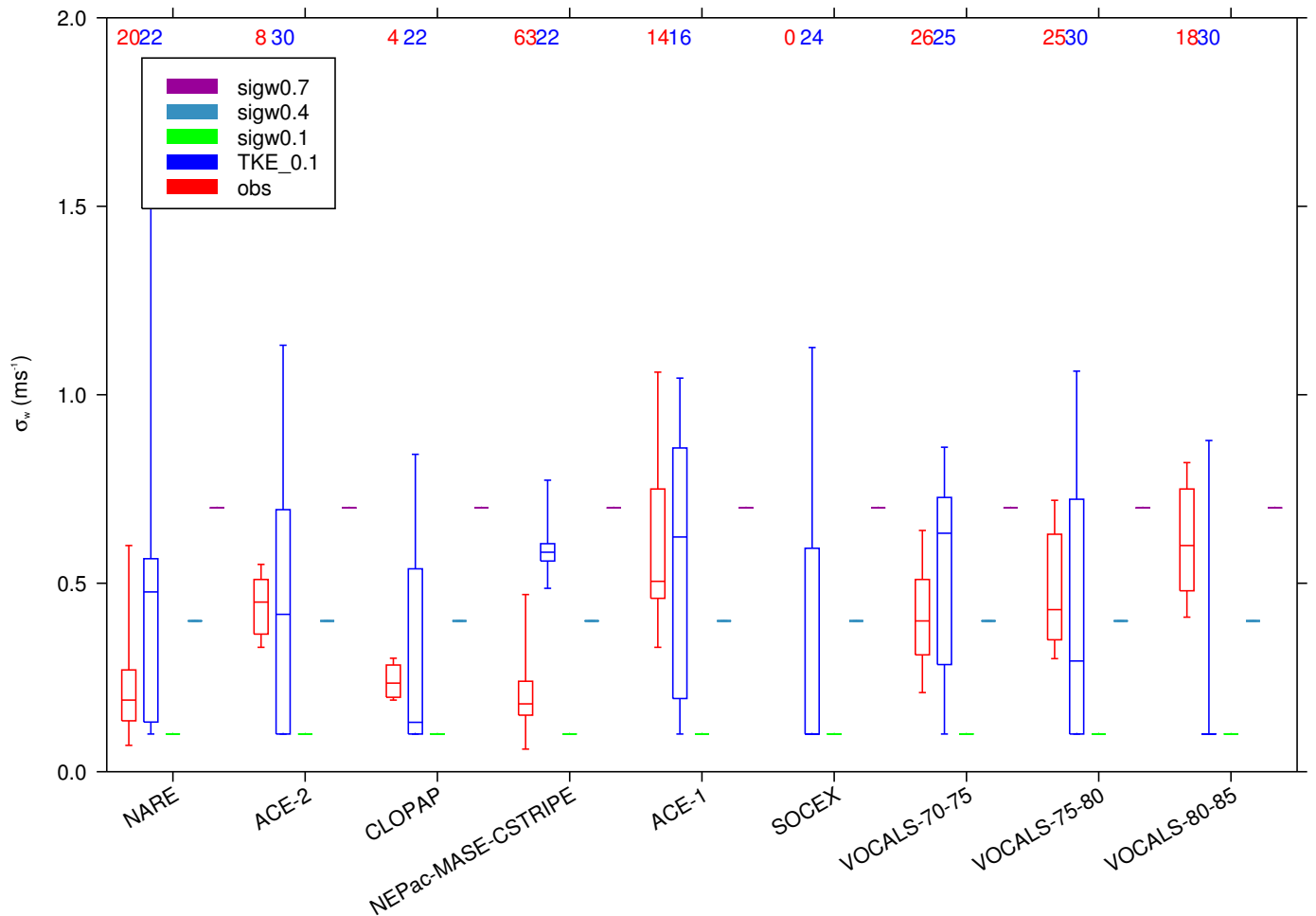

(b) $\sigma_{\mathrm{w}}$ distributions from observations and models

Figure 7b. Continued.

roles, their importance being dependent on how polluted a region is (Partridge et al., 2012).

\subsection{Radiative effects of anthropogenic aerosol}

Estimates of the radiative flux perturbation (RFP) due to total anthropogenic aerosol effects, including direct, semi-direct and indirect aerosol effects (cloud albedo and cloud lifetime), and the couplings between them, are derived from the difference in net radiation at the top of the atmosphere between pairs of parallel GCM simulations with present-day (PD) and pre-industrial (PI) aerosol emissions (e.g. Rotstayn and Penner, 2001; Haywood et al., 2009; Lohmann et al., 2010). A summary of the global mean anthropogenic emissions relevant to aerosols in the pre-industrial and present-day runs is given in Table 4. The energy imbalance at the top of the atmosphere (TOA) ranges from 5.2 to $10.4 \mathrm{~W} \mathrm{~m}^{-2}$ depending on model configuration and aerosol emissions. Since the model was run in atmosphere-only mode for the purposes of this study, some imbalance is inevitable. As with any change to a model that affects radiative fluxes, retuning of the model's TOA radiation imbalance would be required before employing the scheme for coupled atmosphere-ocean integrations, and such retuning is likely to change the RFP.
The global mean RFP due to anthropogenic aerosol effects from each of the vertical velocity configurations is summarised in Table 5 and shown in Fig. 8a.

All four configurations produce a net negative total radiative effect due to anthropogenic aerosols, with estimates of the total global mean RFP ranging from -1.9 to a maximum of $-2.3 \mathrm{~W} \mathrm{~m}^{-2}$, depending on choice of $\sigma_{\mathrm{w}}$. It is possible that such a range could have a significant impact on the temperature evolution from PI to PD conditions in a fully coupled model (e.g. Guo et al., 2013). The magnitude of the total radiative effect increases sub-linearly with increasing $\sigma_{\mathrm{w}}$. Results from an additional pair of simulations with fixed cloud droplet number concentration (not shown) indicate that the RFP due to the direct effect of aerosols alone within HadGEM-UKCA is approximately $-0.6 \mathrm{~W} \mathrm{~m}^{-2}$. Subtracting this value for the direct effect from the four estimates for the total aerosol effects shows the substantial relative variation in magnitude of the modelled indirect aerosol effects due to the choice of $\sigma_{\mathrm{w}}$.

As discussed in the model evaluation in Sect. 3.2.1, increasing $\sigma_{\mathrm{w}}$ tends to increase $\mathrm{CDNC}$, since the increased maximum supersaturations provided by the higher updraught velocities possible with a wider pdf enable more of the smaller aerosols to activate.

Table 6 shows the annual area-weighted mean values of in-cloud droplet number concentration at $720 \mathrm{~m}$ above the 
Table 4. Global emissions from anthropogenic sources for each species considered in this study, for pre-industrial (PI) and present-day (PD) simulations. Emissions for the years 1850 and 2000 are taken from the Coupled Model Intercomparison Project Phase 5 (CMIP5) emissions data set (Lamarque et al., 2010).

\begin{tabular}{lrrr}
\hline Species & PI $\left[\mathrm{Tg} \mathrm{yr}^{-1}\right]$ & $\mathrm{PD}\left[\mathrm{Tg} \mathrm{yr}^{-1}\right]$ & $\mathrm{PD}-\mathrm{PI}\left[\mathrm{Tg} \mathrm{yr}^{-1}\right]$ \\
\hline Black carbon fossil fuel (at surface) & 0.10 & 3.10 & 3.00 \\
Black carbon biofuel (at surface) & 1.17 & 2.12 & 0.95 \\
Organic carbon fossil fuel (at surface) & 0.21 & 4.31 & 4.10 \\
Organic carbon biofuel (at surface) & 5.14 & 8.56 & 3.42 \\
Black carbon biomass (3-D emissions) & 2.06 & 2.65 & 0.59 \\
Organic carbon biomass (3-D emissions) & 25.52 & 32.99 & 7.47 \\
$\mathrm{SO}_{2}$ emissions (at surface) & 1.48 & 37.86 & 36.38 \\
$\mathrm{SO}_{2}$ emissions (high level) & 0.64 & 67.26 & 66.62 \\
\hline
\end{tabular}

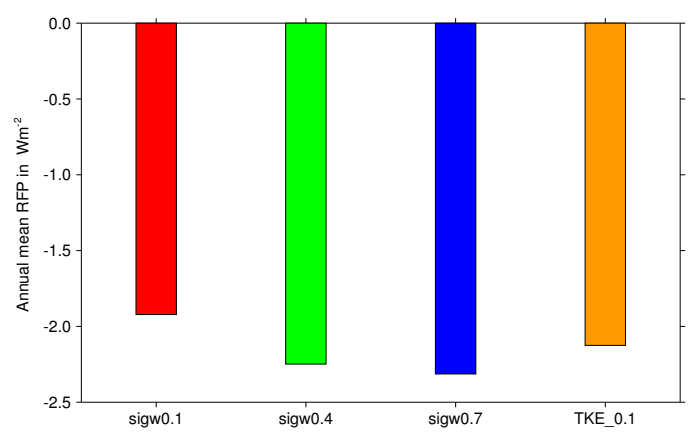

(a) RFP at TOA

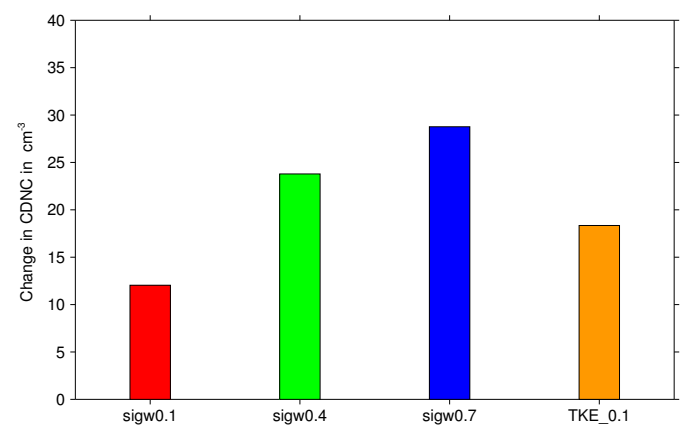

(c) $\triangle \mathrm{CDNC}(\mathrm{PD}-\mathrm{PI})$

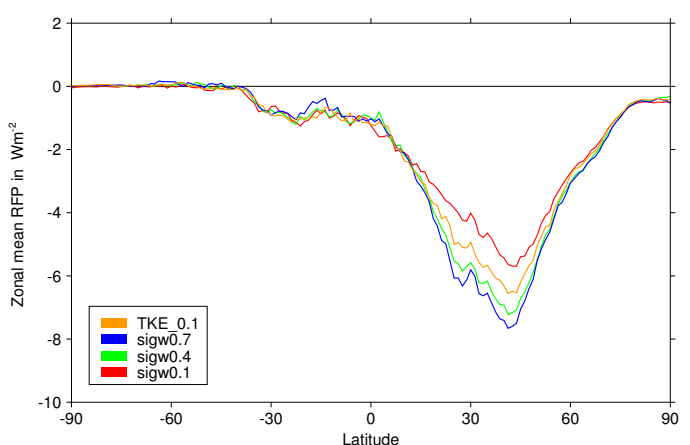

(b) Zonal mean RFP at TOA

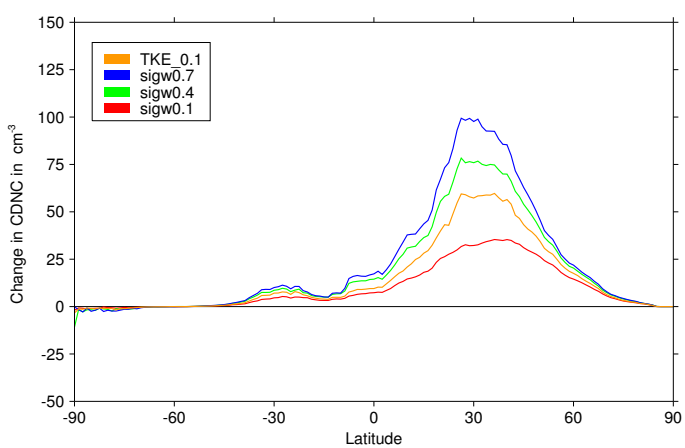

(d) Zonal mean $\triangle \mathrm{CDNC}(\mathrm{PD}-\mathrm{PI})$

Figure 8. RFP due to total anthropogenic aerosol effects and change in annual mean CDNC (at 720 m) for model configurations sigw0.1 (red), sigw0.4 (green), sigw0.7 (blue) and TKE_0.1 (orange). (a) and (c) show differences in global mean (PD - PI); (b) and (d) show differences in zonal mean (PD - PI).

surface, for both pre-industrial and present-day conditions for each model configuration. (The aerosol activation scheme was used in all simulations presented in this paper, and therefore both pre-industrial and present-day CDNC depend on $\sigma_{\mathrm{w}}$ and contribute to the range of indirect aerosol effects.)

When considering pairs of simulations with different aerosol emissions, the magnitude of the change in CDNC between the pre-industrial and present-day runs $(\triangle \mathrm{CDNC})$ also tends to increase with increasing $\sigma_{\mathrm{w}}$, as illustrated in Fig. 8d. For instance, the global mean CDNC in the PI run of sigw0.4 is greater than in the PI run of sigw0.1 but, moreover, the higher $\mathrm{CCN}$ concentrations in both PD runs leads to much more of an increase in $\mathrm{CDNC}$ for the sigw0.4 run than it does for sigw0.1 (i.e. $\triangle \mathrm{CDNC}($ sigw0.4) $>\triangle \mathrm{CDNC}$ (sigw0.1), shown in Fig. 8d), because the faster updraughts (and hence higher supersaturations) mean that more of the greater number of CCN in the PD run can activate in sigw0.4, and hence the indirect aerosol effects are stronger.

Table 7 presents the shortwave cloud radiative effect (SW $\mathrm{CRE}$ ) for both pre-industrial and present-day simulations for 


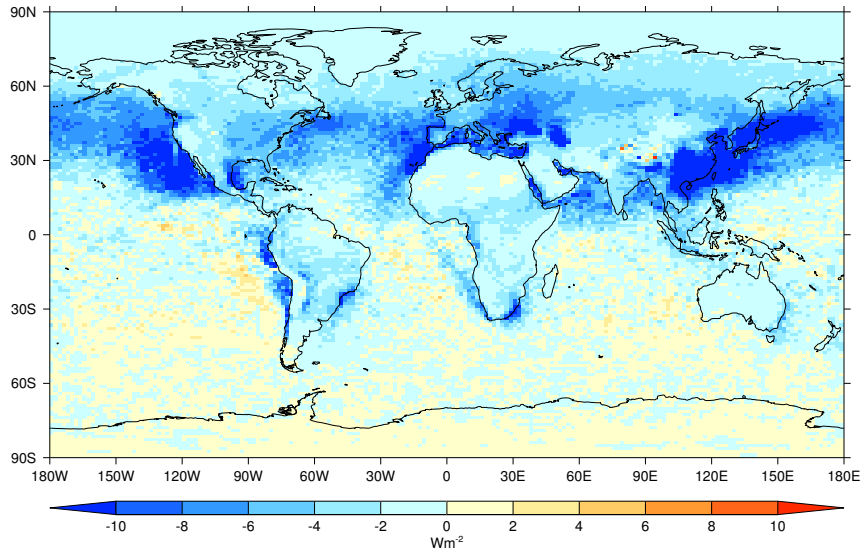

(a) RFP(sigw0.4)

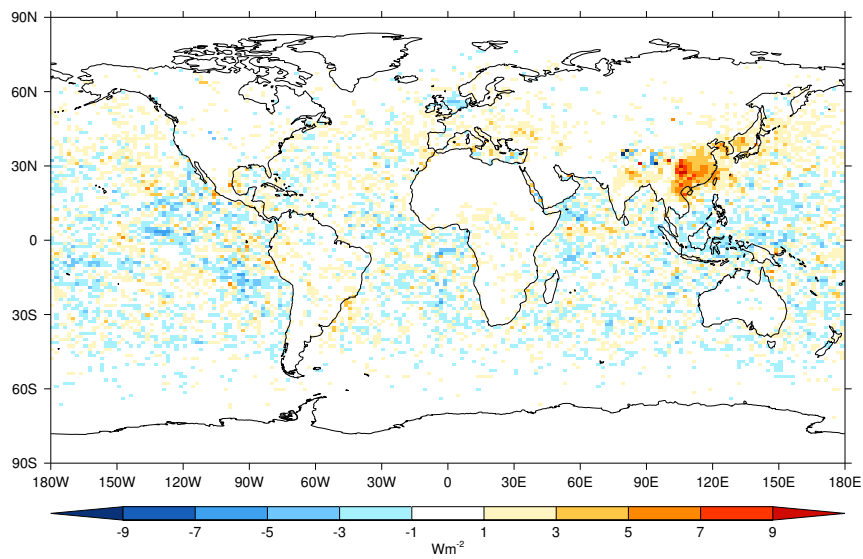

(c) RFP(TKE_0.1) - RFP(sigw0.4)

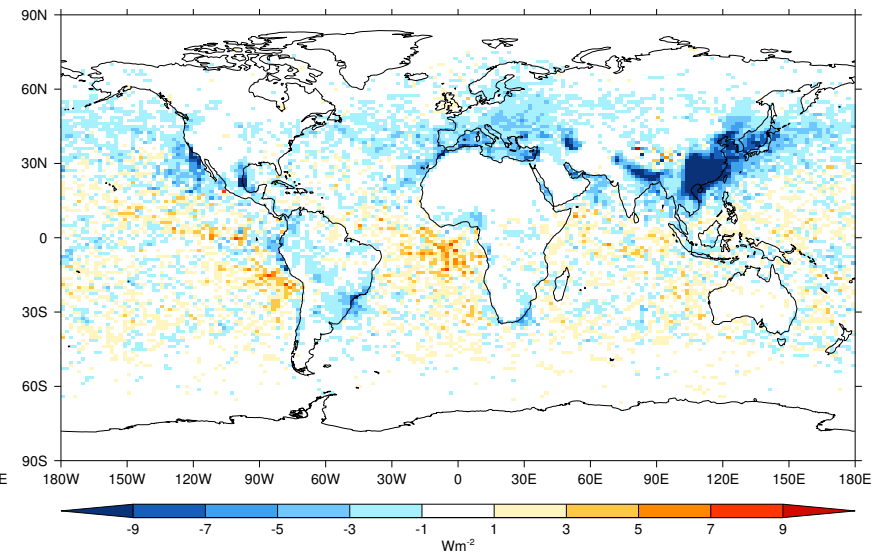

(b) RFP(sigw0.7) - RFP(sigw0.1)

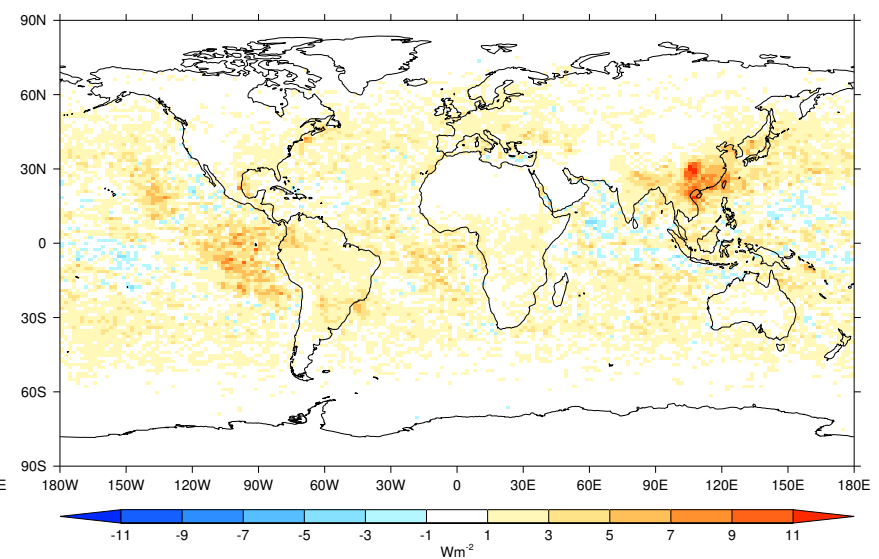

(d) SWCRE(TKE_0.1) - SWCRE(sigw0.4)

Figure 9. Annual mean radiative flux perturbations due to total (direct and indirect) anthropogenic aerosol effects for (a) model sigw0.4 $\left(\mathrm{AWM}=-2.25 \mathrm{~W} \mathrm{~m}^{-2}\right)$. (b) and (c) show differences in annual mean radiative flux perturbations between $(\mathbf{b})$ sigw0.7 - sigw0.1 $(\mathrm{AWM}=$ $\left.-0.39 \mathrm{~W} \mathrm{~m}^{-2}\right)$, and (c) TKE_0.1 - sigw0.4 $\left(\mathrm{AWM}=0.12 \mathrm{Wm}^{-2}\right)$. (d) shows difference in SW CRE for TKE_0.1 - sigw0.4 $($ AWM $=$ $\left.1.18 \mathrm{~W} \mathrm{~m}^{-2}\right)$.

each of the model configurations. The SW CRE increases with increasing $\sigma_{\mathrm{w}}$ for both PI and PD simulations.

A map of the RFP for sigw0.4 is included in Fig. 9a. Figure $9 \mathrm{~b}$ and $\mathrm{c}$ display difference plots of RFPs between selected combinations of model configurations, to highlight the regions where differences manifest themselves in this climatically important quantity.

The most striking features of the map of RFP in Fig. 9a are the regions of strong negative RFP, covering much of the ocean in the Northern Hemisphere. The magnitude of this effect increases with increasing $\sigma_{\mathrm{w}}$. Over land regions, the RFP is also predominantly negative, but less so than over ocean, other than in eastern Europe and sweeping out over China into the Pacific outflow region. In these areas the negative effect also intensifies significantly with increasing $\sigma_{\mathrm{w}}$ (evident in the difference plot of RFP(sigw0.7) - RFP(sigw0.1) in Fig. 9b).
In the Southern Hemisphere, all model configurations show strong localised negative effects off the coast of Chile in the south-east Pacific ocean and also along the coast of southern Africa. However, other than in these regions, much of the Southern Hemisphere (and tropical) oceans are covered by a weak and noisy positive RFP, which raises some questions. What causes the sign difference between the two hemispheres? In particular, what causes the region of elevated positive RFP in the southeastern $\mathrm{Pa}$ cific? A comparison between the model configurations indicates that the intensity of the effect in this region increases with increasing $\sigma_{\mathrm{w}}$ (again, evident in the difference plot of RFP(sigw0.7) - RFP(sigw0.1) in Fig. 9b) and is strongest in configuration sigw0.7. This will be addressed further in Sect. 3.5.

In the global mean, the RFP for TKE_0.1 is lower than that for sigw0.4. As discussed in Sects. 2.4 and 3.2.3, although 
Table 5. Global mean RFPs due to total anthropogenic aerosol effects for each of the vertical velocity configurations in HadGEMUKCA.

\begin{tabular}{lc}
\hline Configuration & $\begin{array}{c}\text { Radiative flux } \\
\text { perturbation }\left[\mathrm{W} \mathrm{m}^{-2}\right]\end{array}$ \\
\hline sigw0.1 & -1.92 \\
sigw0.4 & -2.25 \\
sigw0.7 & -2.31 \\
TKE_0.1 & -2.13 \\
\hline
\end{tabular}

Table 6. Global mean cloud droplet number concentration at $720 \mathrm{~m}$ for each model configuration.

\begin{tabular}{lccc}
\hline Configuration & $\begin{array}{c}\text { CDNC (PI) } \\
{\left[\mathrm{cm}^{-3}\right]}\end{array}$ & $\begin{array}{c}\mathrm{CDNC}(\mathrm{PD}) \\
{\left[\mathrm{cm}^{-3}\right]}\end{array}$ & $\begin{array}{c}\text { Change in CDNC } \\
(\mathrm{PD}-\mathrm{PI})\left[\mathrm{cm}^{-3}\right]\end{array}$ \\
\hline sigw0.1 & 18.41 & 30.46 & 12.04 \\
sigw0.4 & 30.63 & 54.44 & 23.79 \\
sigw0.7 & 36.19 & 64.99 & 28.77 \\
TKE_0.1 & 23.56 & 41.91 & 18.35 \\
\hline
\end{tabular}

there are several regions where $\sigma_{\mathrm{w}}$ derived from TKE exceeds $0.4 \mathrm{~m} \mathrm{~s}^{-1}$ (as shown for runs of TKE_0.1 compared to sigw0.4 with present-day aerosol in Fig. 4), the high frequency of occurrence of the minimum value of $\sigma_{\mathrm{w}}^{\min }$ in TKE_0.1 brings down the average value of $\sigma_{\mathrm{w}}$. Both positive and negative features of the map of RFP for TKE_0.1 are reduced in intensity, compared to sigw0.4, as shown in Fig. 9c. Although allowing $\sigma_{\mathrm{w}}$ to depend on TKE produces some regions in which $\sigma_{\mathrm{w}}>0.4 \mathrm{~m} \mathrm{~s}^{-1}$, this does not lead to noticeable increases in CDNC, compared to that obtained with sigw0.4 (illustrated in Fig. 4a compared to $b$ for present-day aerosol) because, in these regions, CDNC tends to be limited by the number of available $\mathrm{CCN}$ rather than updraught. This is particularly true in the marine stratocumulus regions.

Table 8 shows the difference in present-day SW CRE between pairs of model configurations. The spatial distribution of local features of the CRE between the TKE_0.1 and sigw0.4 is displayed in Fig. 9d and closely mirrors the difference in RFP between those configurations shown in Fig. 9c.

The range of values of RFP generated by the four different vertical velocity configurations provides some quantification of uncertainty in estimates of the RFP due to the choice of parameterisation of vertical velocity. Figure $8 \mathrm{~b}$ shows the zonal mean RFP due to anthropogenic aerosol effects for each of configurations sigw0.1, sigw0.4, sigw0.7 and TKE_0.1. The overall increasing magnitude of negative effects in the Northern Hemisphere with increasing $\sigma_{\mathrm{w}}$ is more clearly visible here than in the maps shown previously. The behaviour of TKE_0.1 is shown to be closer to sigw0.4 than sigw0.1, as expected from the global mean RFP in Fig. 8a. The near-zero zonal average RFP in the Southern Hemisphere masks significant regional variation, which will be discussed in Sect. 3.5.
Table 7. Global mean shortwave cloud radiative effect (SW CRE) for each model configuration.

\begin{tabular}{lcc}
\hline Configuration & $\begin{array}{c}\text { SW CRE (PI) } \\
{\left[\mathrm{W} \mathrm{m}^{-2}\right]}\end{array}$ & $\begin{array}{c}\text { SW CRE (PD) } \\
{\left[\mathrm{W} \mathrm{m}^{-2}\right]}\end{array}$ \\
\hline sigw0.1 & -38.18 & -39.10 \\
sigw0.4 & -40.56 & -41.83 \\
sigw0.7 & -41.35 & -42.66 \\
TKE_0.1 & -39.53 & -40.65 \\
\hline
\end{tabular}

Table 8. Difference in global mean SW cloud radiative effect between pairs of present-day simulations from different model configurations.

\begin{tabular}{|c|c|}
\hline Configurations & $\begin{array}{r}\text { Difference in SW CRE } \\
(\mathrm{PD})\left[\mathrm{W} \mathrm{m}^{-2}\right]\end{array}$ \\
\hline $\begin{array}{l}\text { TKE_0.1 - sigw0.4 } \\
\text { sigw0.7 -sigw0.1 }\end{array}$ & $\begin{array}{r}1.18 \\
-3.56\end{array}$ \\
\hline
\end{tabular}

As described in Sect. 2.4, the choices of $\sigma_{\mathrm{w}}$ for sigw0.1 and sigw0.7 cover the range of the majority of the observed values of $\sigma_{\mathrm{w}}$ recorded in the flight campaigns listed in Table 3 , with very few exceptions. The limited spatial and temporal sampling of this set of observations notwithstanding, it is assumed that the range of values in the whole set is broadly representative of $\sigma_{\mathrm{w}}$ in boundary layer stratiform cloud. Should a fixed value of $\sigma_{\mathrm{W}}$ be required for a GCM, within the boundary layer, it should fall in the range $0.1<\sigma_{\mathrm{w}}<0.7 \mathrm{~ms}^{-1}$. Although there may be individual instances where $\sigma_{\mathrm{w}}$ exceeds these values, to choose a fixed value of $\sigma_{\mathrm{w}}$ outside of this range to be applied globally would be grossly misrepresentative.

The annual mean RFPs from these two runs therefore provide an upper and lower bound on the effect of the choice of vertical velocity parameterisation on estimates of the RFP in HadGEM-UKCA due to anthropogenic aerosols of -1.9 to $-2.3 \mathrm{~W} \mathrm{~m}^{-2}$. This range is likely to be more sensitive to the choice of bounds at the low end, because the sub-linear dependence of $\triangle \mathrm{CDNC}$ (i.e. PD - PI) on $\sigma_{\mathrm{w}}$ saturates with increasing $\sigma_{\mathrm{w}}$, and therefore it would be most beneficial to focus further study on forming a tighter constraint on the low end of the range.

As shown in Fig. 7a, both TKE_0.1 and sigw0.4 generate CDNCs that compare reasonably well with those measured in marine stratiform clouds, which provides a degree of confidence in the estimates of the RFP. However, the comparisons against the in situ measurements do not provide enough information to quantify whether sigw0.4 or TKE_0.1 is a better choice of vertical velocity parameterisation to be applied globally. In light of the temporal and spatial variability of $\sigma_{\mathrm{w}}$ shown by the flight campaigns, a parameterisation in which $\sigma_{\mathrm{w}}$ also has the potential to vary is a more physically representative choice than one in which $\sigma_{\mathrm{w}}$ has a fixed value. 
However, the assumption that this variability can be meaningfully approximated by a Gaussian pdf with $\sigma_{\mathrm{w}}=\sqrt{\frac{2}{3} \mathrm{TKE}}$ is still open to further evaluation, and there also remain considerable uncertainties in the calculation of TKE itself. It has been proposed that there may be other parameterisations that are more suitable for particular cloud regimes. For example, Hoose et al. (2010) demonstrated that a liquid water content (LWC)-based parameterisation can work better than a turbulence-based parameterisation for cumulus cloud types. Thus there may be improvements to be made by using cloud regime-dependent parameterisations within GCMs. In the meantime, TKE_0.1 is applied as the default setting for HadGEM-UKCA, with the recommendations that technical issues of high frequency of occurrence of $\sigma_{\mathrm{w}}^{\min }$ (due to the lowest cloudy level falling between or just outside the turbulent layers, and the lack of properly resolved convective updraughts), and the choice of $\sigma_{\mathrm{w}}^{\mathrm{min}}$ above the boundary layer, be addressed as a matter of urgency.

\subsection{Influence of aerosol microphysics}

A slightly surprising feature of the RFP maps shown in Fig. 9 is the positive values visible in the Southern Hemisphere, and in particular the region of elevated positive forcing in the southeastern Pacific. A possible explanation for this is found by considering the microphysical aerosol processes at work in UKCA.

\subsubsection{Aerosol mass distributions}

The annual mean aerosol burden of each of sulfate, black carbon and organic carbon are shown in Fig. 10.

Results are shown for pairs of runs of model configuration sigw0.4 and illustrate the difference in resulting aerosol burden of each component between pre-industrial and present day aerosol emissions.

On average, the sulfate burden has tripled between the PI and PD runs, but the maps show that the increase is far stronger in the Northern Hemisphere (tenfold increases in some regions) than the southern (typical increases of 40 to $80 \%)$. Over land, increases are particularly strong in the industrialised and heavily populated regions of China, India, the Middle East, eastern North America and much of Eurasia. Sulfate burden has also at least doubled over most of the ocean in the Northern Hemisphere and along the major shipping routes through the Southern Hemisphere. This large increase in the mass of sulfate in the Northern Hemisphere is a major contributing factor to the strong negative RFP seen in the Northern Hemisphere, due to the increase in CCN, although exact details are of course dependent on the size and number distribution of this increased mass. The sharp contrast between the hemispheres visible in the difference plot of sulfate burden in Fig. 10a is clearly followed through to the contrast between the same regions in the RFP shown in Fig. 9a.
Increases in the black carbon burden due to a combination of fossil fuel combustion and biomass burning has produced a doubling of the global average burden, and substantially greater increases in localised regions. Significant relative increases (not shown) have occurred over China and Indonesia, and over the Amazon, sweeping out across the tropical Pacific. Over eastern North America, the North Atlantic and northern Europe, the black carbon burden has slightly decreased. The global mean burden of organic carbon has increased $25 \%$ between the PI and PD runs, with strong increases in the biomass burning regions and over China. Similar to black carbon, 40-60\% decreases have occurred over North America, the North Atlantic and northern Europe. The decreases in black carbon and organic carbon over North America arise because of the substantial amount of biomass burning in the 1900 baseline that is used throughout 18502000 in the BC/OC emissions for IPCC AR5 (see Lamarque et al., 2010). The sea salt and dust burdens have not changed between the two simulations (not shown).

\subsubsection{Aerosol number distributions}

While the difference in total mass of each component is determined by the differences between the prescribed preindustrial and present-day emissions, the number and size distribution of particles is controlled by $\mathrm{UKCA}^{1}$. The way in which this mass is distributed in terms of particle size and number can significantly affect the CDNC and hence the indirect aerosol effects.

In the map of RFP shown in Fig. 9, a weak positive effect is visible over the tropical oceans and the oceans of the Southern Hemisphere. This positive region still remains once the direct aerosol effects have been subtracted out from the total effects (not shown). This positive effect is strongest in a region of the southeastern Pacific, and increases in intensity with increasing $\sigma_{\mathrm{w}}$.

The cloud fraction in this region does not change significantly between the PI and PD runs (not shown). The effect must therefore be brought about by the difference between cloud droplet number concentrations in runs with PI and PD aerosol emissions. Figure 11a shows that the number of cloud droplets is lower in the PD run compared to PI, in the region of positive RFP.

To confirm the existence of changes in cloud-relevant aerosol number, Fig. $11 \mathrm{~b}$ shows a map of the change in $\mathrm{CCN}$ at fixed supersaturation between runs of sigw0.4 with preindustrial and present day aerosol emissions. (A high supersaturation of $S=1 \%$ is chosen to emphasise contrasts.) A decrease in the number of $\mathrm{CCN}$ is visible in the relevant region, indicating that the number of CDNC decreases because there are fewer aerosols which may be activated in the region.

\footnotetext{
${ }^{1}$ The assumed size distribution of the primary emissions exerts a strong influence on simulated particle number (Spracklen et al., 2011) and size distribution (Reddington et al., 2013).
} 


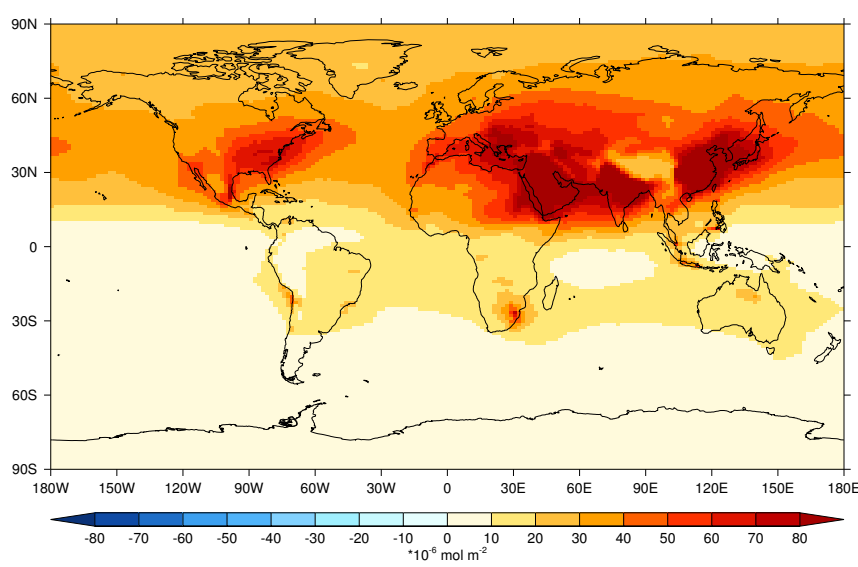

(a) Sulfate (PD - PI)

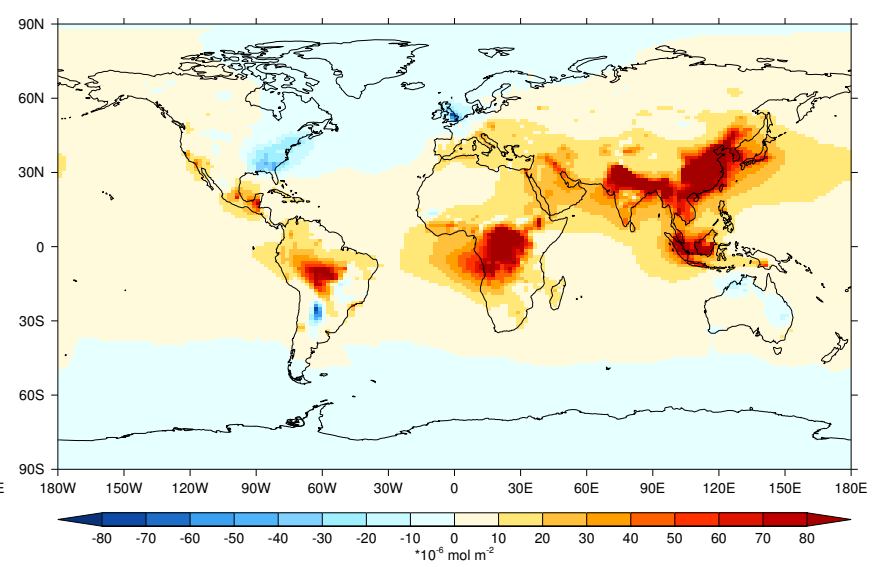

(b) Black carbon (PD - PI)

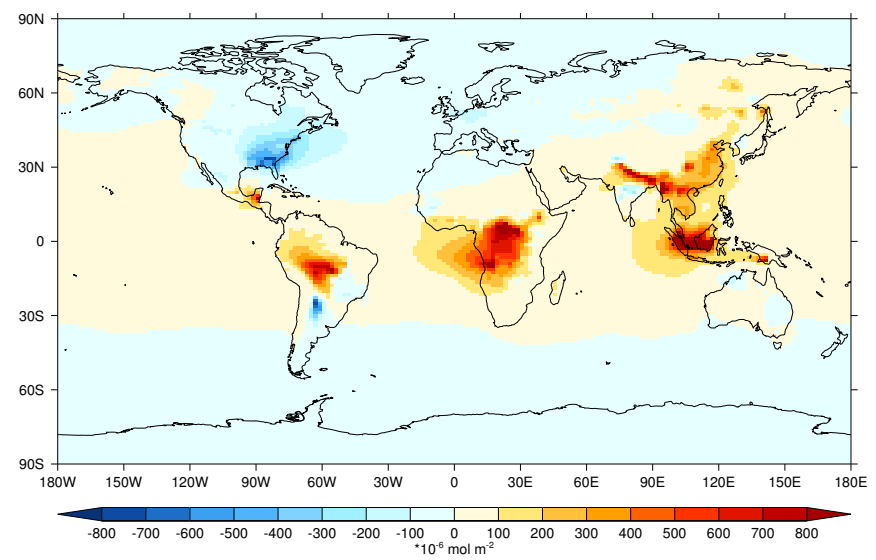

(c) Organic carbon (PD - PI)

Figure 10. Change in annual mean aerosol burden by component: (a) sulfate $\left(\mathrm{AWM}=23.06 \times 10^{-6} \mathrm{molm}^{-2}\right),(\mathbf{b})$ black carbon $(\mathrm{AWM}=$ $\left.8.77 \times 10^{-6} \mathrm{~mol} \mathrm{~m}^{-2}\right)$, and (c) organic carbon $\left(\mathrm{AWM}=31.26 \times 10^{-6} \mathrm{~mol} \mathrm{~m}^{-2}\right)$. All results from pairs of runs of model sigw0.4 run with pre-industrial and present-day aerosol emissions; figures show absolute differences (PD - PI) between pairs of runs.

The response of the RFP in fixed $\sigma_{\mathrm{w}}$ runs provides further information. We have shown that CDNC increases with increasing $\sigma_{\mathrm{w}}$, because increasing $\sigma_{\mathrm{w}}$ can increase $S_{\max }$, which causes $a_{\min }$ (the dry radius of the smallest particle which activates) to be lower, which means that more of the smaller particles can be activated in the higher updraughts. Further, the magnitude of $\triangle \mathrm{CDNC}$ between PD and PI - both positive and negative - increases with increasing $\sigma_{\mathrm{w}}$. This could be the result of a number of different effects: a simple increase in the total number of soluble aerosols, while the distribution kept the same shape, or more complex changes to the distribution of size, number, mass, or composition between PI and $\mathrm{PD}$ runs, as a result of microphysical aerosol interaction.

So, is the number of small, soluble aerosols lower in the PD than PI runs in this region? And if so, why?

Figure 12 shows the change in annual mean number burden (column-integrated aerosol number concentration) between pre-industrial and present day simulations for four of the size modes used in this configuration of UKCA, three soluble aerosol modes (nucleation, Aitken, accumulation) and the insoluble Aitken mode. The possible constituent components of each of these modes is listed in Table 1.

Both soluble nucleation and Aitken modes show a decrease in the number of particles in the relevant region from PI to PD runs of between 20 and $40 \%$. It is evident that despite increased $\mathrm{SO}_{2}$ emissions (not shown, but implied by increase in sulfate burden shown previously in Fig. 10), fewer new sulfate particles nucleate in PD conditions, and there are subsequently fewer sulfate particles that can grow into the Aitken mode. The absolute decrease of Aitken mode particles is particularly strong across the tropical Pacific, which corresponds to the region of elevated positive RFP seen in Fig. 9a.

By contrast, the number burden of aerosols in the soluble accumulation mode has increased almost universally in the PD compared to PI run, as shown in Fig. 12c, and has 


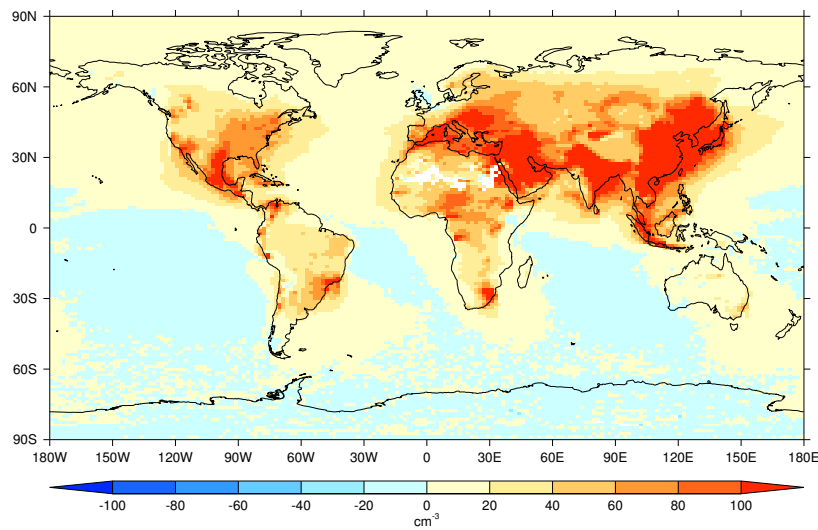

(a) $\triangle \mathrm{CDNC}$ in sigw0.4 (PD - PI)

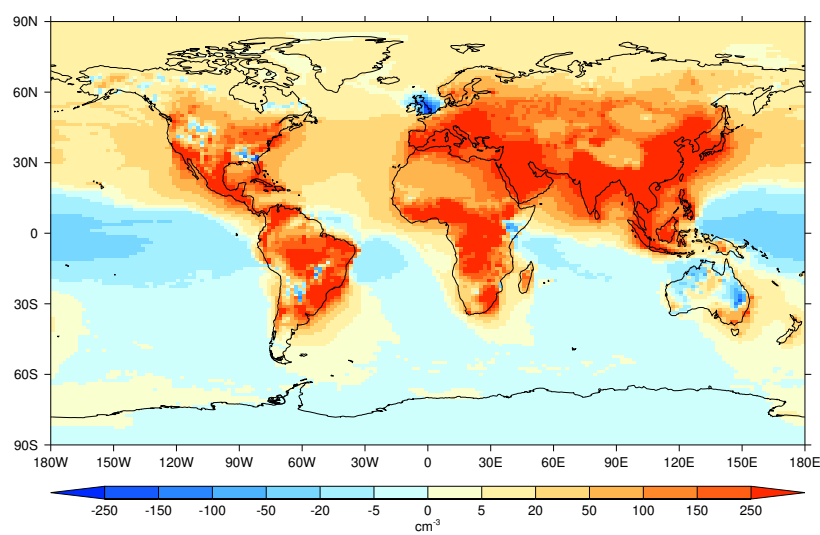

(b) $\triangle \mathrm{CCN}$ sigw0.4 (PD - PI)

Figure 11. Change in annual mean (a) $\mathrm{CDNC}$ at $720 \mathrm{~m}(\mathrm{AWM}=$ $\left.23.8 \mathrm{~cm}^{-3}\right)$ and (b) $\mathrm{CCN}$ at $S=1 \%\left(\mathrm{AWM}=81.6 \mathrm{~cm}^{-3}\right)$, in model sigw0.4. Maps show absolute difference between a pair of simulations with pre-industrial and present-day aerosol emissions (PD - PI). Note non-linear colour bar in (b).

doubled on average. Strong increases (up to eightfold) are notable in both biomass burning and industrial regions, and relative increases of between 60 and $80 \%$ occur in more remote regions, such as across the southern Pacific.

The number of particles in the coarse soluble mode is dominated by sea salt, and shows very little change between runs with pre-industrial and present-day aerosol emissions (not shown).

Number burdens of the insoluble Aitken mode are shown in Fig. 12d. Emissions of insoluble particles in the industrial and biomass burning regions increase between PI and PD emissions, which leads to the strong increase seen across south-east Asia, the Indian Ocean and the tropical Pacific. Although insoluble aerosols cannot themselves act as CCN, interactions with soluble components lead to indirect influences, for example, via coagulation with soluble particles and condensation of soluble components.

\subsubsection{Suppression of nucleation}

A possible explanation for the suppression of nucleation of fresh sulfate particles and subsequent reduction in the number of CCN-relevant soluble Aitken mode particles in the southeastern Pacific is that the increased number of soluble accumulation and insoluble Aitken mode particles in this previously pristine region provides an increased surface area on to which $\mathrm{H}_{2} \mathrm{SO}_{4}$ vapour can condense. This process of condensation on to existing particles is more energetically favourable than new particle formation, and thus occurs preferentially, effectively shutting off a large fraction of the particle nucleation. The importance of the condensation sink of pre-existing particles has been demonstrated in other aerosol modelling studies, for example, Tunved et al. (2010) showed that the condensational sink of existing particles dominates in polluted regions, and that the nucleation of fresh particles only contributes to particle number in clean air masses.

Conversely, the number of nucleation mode particles has a strong relative increase over North America, the North Atlantic and Northern Europe potentially due to the inverse of the same process, as these are regions where the number of insoluble Aitken particles decreases.

However, to complicate matters, in regions such as southeast Asia, nucleation of sulfate particles increases substantially despite an increase in both accumulation and insoluble Aitken mode numbers. This is possibly because the absolute abundance of $\mathrm{SO}_{2}$ emitted in this region in the PD run is so large, that, following oxidation, sulfate aerosol nucleation occurs regardless of the additional condensational sink provided by additional larger particles.

The complex interplay between the microphysical aerosol processes represented within UKCA, combined with the highly non-linear aerosol activation scheme, leads to responses to perturbations that would be impossible to predict from physical intuition alone. These responses are shown to play out in the climate-relevant radiative effects, which underlines the importance of the inclusion of microphysical aerosol modelling in GCMs.

\section{Summary and conclusions}

The aim of this study was to investigate how the representation of subgrid-scale vertical velocity variability within a GCM affects estimates of the indirect aerosol effects. We present the radiative flux perturbations due to anthropogenic aerosols in HadGEM-UKCA using the Abdul-Razzak and Ghan (2000) aerosol activation scheme, with four different configurations of vertical velocity. We have shown that use of a single, characteristic updraught is a needless oversimplification, compared to the pdf-based approach. Main results illustrate how increasing the standard deviation of a Gaussian pdf of vertical velocity globally from $\sigma_{\mathrm{w}}=$ $0.1 \mathrm{~m} \mathrm{~s}^{-1}$ to $0.7 \mathrm{~m} \mathrm{~s}^{-1}$ generates RFPs of total anthropogenic 


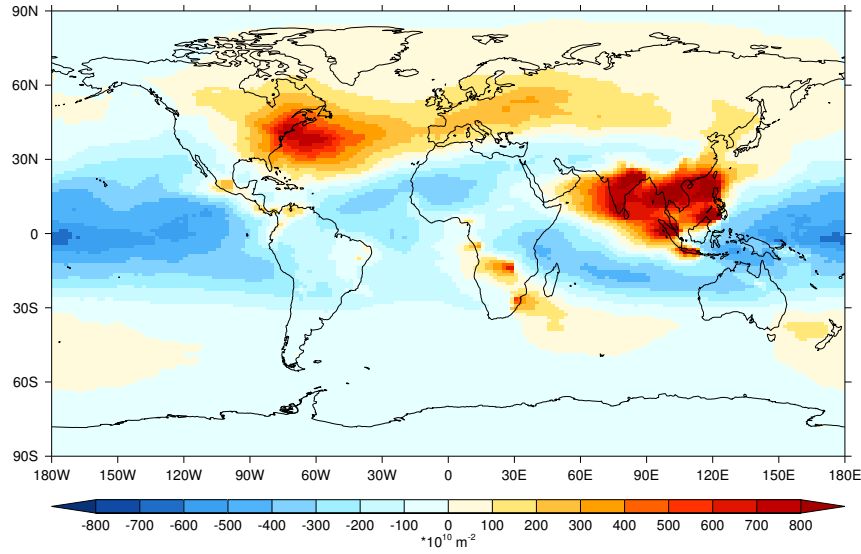

(a) Soluble nucleation mode (PD - PI)

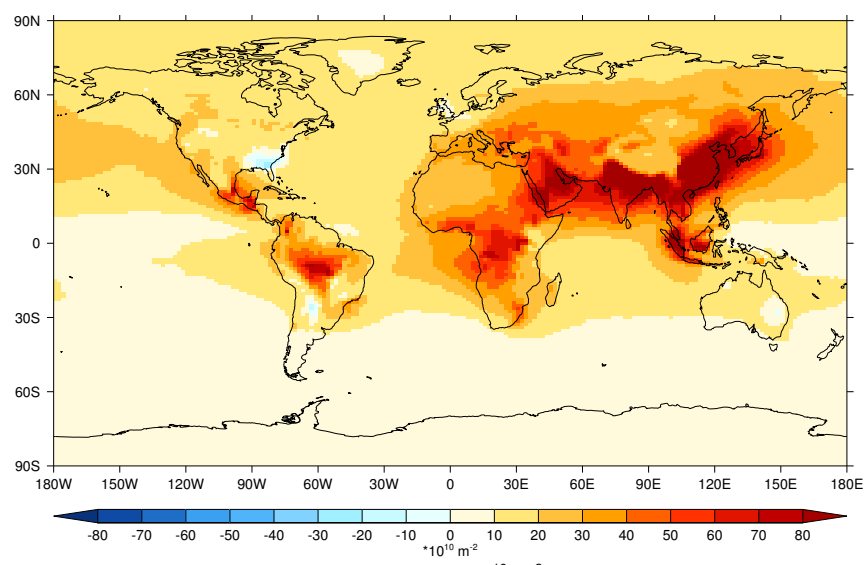

(c) Soluble accumulation mode (PD - PI)

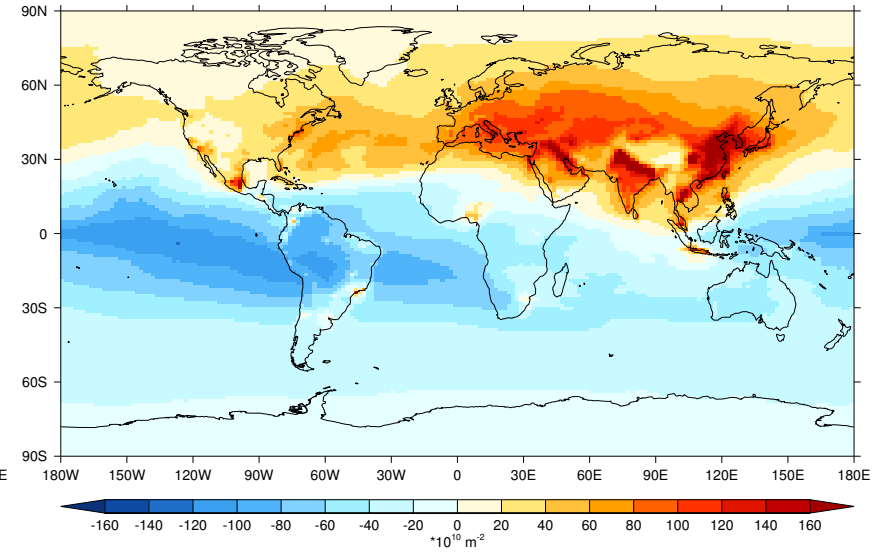

(b) Soluble Aitken mode (PD - PI)

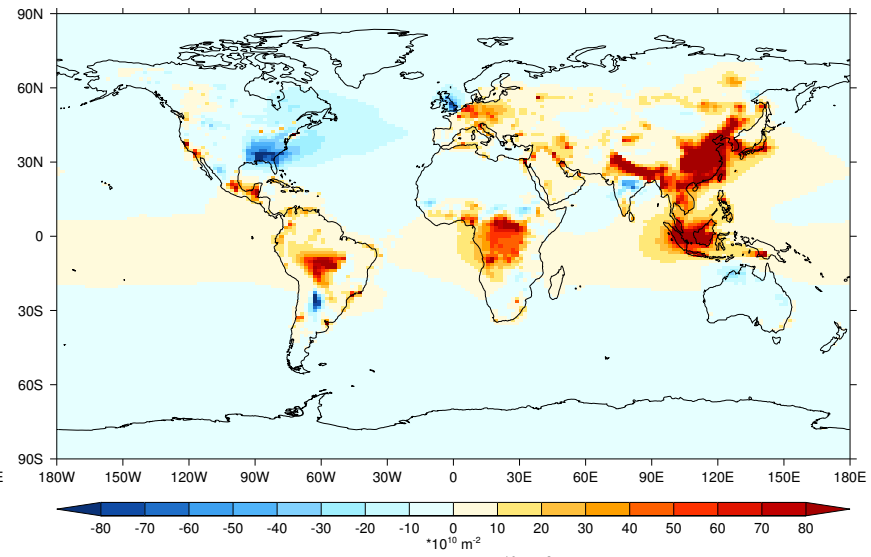

(d) Insoluble Aitken mode (PD - PI)

Figure 12. Change in annual mean aerosol number burden in (a) soluble nucleation mode, $\left(\mathrm{AWM}=-57.00 \times 10^{10} \mathrm{~m}^{-2}\right)(\mathbf{b})$ soluble Aitken mode $\left(\mathrm{AWM}=-13.02 \times 10^{10} \mathrm{~m}^{-2}\right)$, (c) soluble accumulation mode $\left(\mathrm{AWM}=19.47 \times 10^{10} \mathrm{~m}^{-2}\right)$, and (d) insoluble Aitken mode $\left(A W M=3.13 \times 10^{10} \mathrm{~m}^{-2}\right)$. Maps show differences between pairs of simulations of model sigw0.4 with pre-industrial and present-day aerosol emissions.

aerosol effects ranging from $-1.9 \mathrm{Wm}^{-2}$ to a maximum of $-2.3 \mathrm{~W} \mathrm{~m}^{-2}$. (Absolute values may change dependent on aerosol activation parameterisation.) The magnitude of RFP increases with $\sigma_{\mathrm{w}}$, but this effect saturates locally once all potential CCN have activated. The uncertainty due to the choice of $\sigma_{\mathrm{w}}$ results in a forcing range which is a substantial fraction of the total diversity of aerosol forcing estimates of $-1.5 \pm 0.5 \mathrm{~W} \mathrm{~m}^{-2}$, found in the Quaas et al. (2009) AeroCOM intercomparison study, involving ten GCMs and relationships derived from satellite data.

While the range of $\sigma_{\mathrm{w}}$ explored here extends to the extremes of what would be a physically reasonable approximation to apply globally for stratiform clouds, it demonstrates how the choice of this parameter in the vertical velocity parameterisation can have a significant impact on the RFP estimate of a model, and thus the importance of using an em- pirically verified choice of vertical velocity parameterisation when modelling indirect aerosol effects.

Examining the difference between maps of RFP with different values of $\sigma_{\mathrm{w}}$ highlights the regions where changing $\sigma_{\mathrm{w}}$ has the greatest effect on CDNC that is most relevant to the RFP. This procedure indicates that cloud regimes could be considered to fall into two categories: those in which the CDNC is limited by the available $\mathrm{CCN}$ and those limited by the local vertical velocities. There are parallels here with work by Reutter et al. (2009), which also identified vertical velocity-limited and $\mathrm{CCN}$-limited regimes for cloud activation in convective clouds.

Most flight campaigns studying aerosol-cloud interactions have focused on marine stratocumulus clouds, in the first of these categories, where the CDNC tends to be limited by the number of $\mathrm{CCN}$, rather than the updraught velocity. It is therefore of great importance to have detailed and accurate 
measurements of $\mathrm{CCN}$ in these regions. However, in terms of vertical velocity measurement, results from this study indicate that inaccuracies in choice of $\sigma_{\mathrm{w}}$ for a GCM can have the most impact in other frequently cloudy regions with high $\mathrm{CCN}$ concentrations, particularly in the industrialised and heavily polluted regions of the Northern Hemisphere, such as China and East Asia, the Ganges Plain and, to a lesser extent, the whole of eastern Europe. In these regions, it is particularly important to use a realistic pdf of vertical velocities, since these are the regions in which the RFP is most affected by the presence of stronger updraughts. For the purposes of reducing the uncertainty in estimates of the indirect aerosol effects due to the parameterisation of vertical velocity it would be particularly useful to have more measurements of the vertical velocity distributions in continental stratiform and shallow cumulus clouds in these regions. This should inform the location and focus of future flight campaigns.

In terms of the best estimate of RFP from HadGEMUKCA, there is insufficient evidence to make the choice between TKE_0.1 $\left(\right.$ RFP $\left.=-2.1 \mathrm{~W} \mathrm{~m}^{-2}\right)$ and sigw0.4 $(\mathrm{RFP}=-$ $2.3 \mathrm{~W} \mathrm{~m}^{-2}$ ). While the spatial and temporal variability of $\sigma_{\mathrm{w}}$ found in TKE_0.1 is more realistic than applying a fixed value of $\sigma_{\mathrm{w}}=0.4 \mathrm{~m} \mathrm{~s}^{-1}$ everywhere, technical restrictions within the current configuration of HadGEM-UKCA (such as the absence of a TKE diagnostic above the planetary boundary layer, and the lack of properly resolved convective updraughts) causes an unrealistically high frequency of occurrence of the minimum value in this configuration $(58 \%)$. The fixed value of $l=40 \mathrm{~m}$ imposed outside the planetary boundary layer for the calculation of TKE via Eq. (6) is likely to be much smaller than $\Delta z$ in Ghan et al. (1997) and hence $\sigma_{\mathrm{w}}$, calculated via Eq. (7), will be larger. This might partially explain the difference in how often the minimum value is imposed here (58\% frequency of occurrence of $0.1 \mathrm{~m} \mathrm{~s}^{-1}$ ), compared to similar work by Golaz et al. (2011) (98\% occurrence of $0.7 \mathrm{~m} \mathrm{~s}^{-1}$ ).

In the spatial differences between the RFPs of TKE_0.1 and sigw0.4 shown in Fig. 9c, attention is drawn to two points. First, as for the difference between sigw0.7 and sigw0.1, the largest $\triangle \mathrm{RFP}$ is seen in a region of high CCN concentration over China. In this region the TKE-derived $\sigma_{\mathrm{w}}$ obtained with TKE_0.1 is usually below $0.4 \mathrm{~m} \mathrm{~s}^{-1}$, hence fewer aerosols activate and the indirect aerosol effects are weaker than in sigw0.4. Measurements of $\sigma_{\mathrm{w}}$ in such cloud regimes would be helpful in choosing between these two model configurations.

The second point relates to the absence of a notable $\Delta$ RFP signal in the persistent marine stratocumulus regions. In Fig. 4, the highest values of $\sigma_{\mathrm{w}}$ in TKE_0.1 were found to be in the stratocumulus regions off the west coasts of North and South America. However, there is little change in the RFP in these regions between the TKE_0.1 and sigw0.4 models because a high fraction of activation can be obtained with relatively low updraught velocities; here, it is the number of potential CCN which is the limiting factor on CDNC. Thus there are several climatically important regions where accuracy in aerosol modelling can have a greater impact on the indirect aerosol effects than the parameterisation of the activation of those aerosols to cloud droplets.

In fact, closer scrutiny of the differences in columnintegrated aerosol mass and number, in Figs. 10 and 12 respectively, shows that the aerosol microphysics can result in somewhat unexpected behaviour under a present-day aerosol emissions scenario compared to pre-industrial, particularly in remote regions. In pre-industrial conditions, a major source of aerosol in these regions is due to the production of new particles via the nucleation of sulfuric acid vapour. However, under present-day aerosol emissions, the increased number of soluble accumulation and insoluble Aitken mode particles in the vicinity provides a large condensational sink for the $\mathrm{H}_{2} \mathrm{SO}_{4}$ vapour, and greatly reduces the number of $\mathrm{CCN}$ produced via the new particle nucleation process. This in turn results in a reduction of the number of CCN compared to pre-industrial times (e.g. in the Southern Hemisphere), and hence the sign of the indirect aerosol effects are seen to be reversed in these regions, resulting in areas of weakly positive RFP.

The modelling of indirect aerosol effects is dependent on accurate $\mathrm{CCN}$ concentrations, which are a result of the interactions of several highly non-linear aerosol microphysical processes. Thus, responses to differing aerosol emissions scenarios are difficult to predict without a detailed model of these processes. What fraction of these potential CCN then actually activate to become cloud droplets is further dependent on the highly non-linear parameterisation of aerosol activation. The response of the climate to this combination of non-linearities underpinning aerosol-cloud interactions is beginning to be understood through the coupling of such microphysical aerosol and cloud processes with dynamical processes such as turbulence and vertical velocity in GCMs.

Future developments in this field would be enabled by a more comprehensive array of in situ measurements that systematically characterises the vertical velocity distributions in different cloud regimes to evaluate the parameterised values of $\sigma_{\mathrm{w}}$ and hence CDNC in a greater variety of conditions. The uncertainty in the indirect aerosol effects could be reduced further by the continued development of better, and potentially non-Gaussian, parameterisations of the pdf for GCM purposes. This could be derived from process studies in highresolution numerical models, combined with more measurements. The representation of more complex distributions that capture the skewness and other higher-order moments of the distribution could also then be warranted, if the results were validated against a more comprehensive survey of in-cloud velocity distributions provided by future flight campaigns. 
Acknowledgements. R. E. L. West and Z. Kipling both acknowledge the support of NERC studentships and receipt of CASE awards from the Met Office during the course of this work. P. Stier's research leading to these results has received funding from the European Research Council under the European Union's Seventh Framework Programme (FP7/2007-2013)/ERC grant agreement no. FP7-280025. A. Jones, C. E. Johnson and N. Bellouin were supported by the Joint DECC/Defra Met Office Hadley Centre Climate Programme (GA01101). Computing resources and support were provided by the Met Office/NERC Joint Weather and Climate Research Programme (JWCRP).

Edited by: C. Hoose

\section{References}

Abdul-Razzak, H. and Ghan, S. J.: A parameterization of aerosol activation 2. Multiple aerosol types, J. Geophys. Res., 105, 68376844, doi:10.1029/1999JD901161, 2000.

Abdul-Razzak, H., Ghan, S. J., and Rivera-Carpio, C.: A parameterization of aerosol activation 1. Single Aerosol Type, J. Geophys. Res., 103, 6123-6131, doi:10.1029/97JD03735, 1998.

Albrecht, B. A., Randall, D. A., and Nicholls, S.: Observations of marine stratocumulus clouds during FIRE, B. Am. Meteorol. Soc., 69, 618-626, doi:10.1175/15200477(1988)069<0618:OOMSCD>2.0.CO;2, 1988.

Albrecht, B. A., Bretherton, C. S., Johnson, D., Scubert, W. H., and Frisch, A. S.: The Atlantic Stratocumulus Transition Experiment - ASTEX, B. Am. Meteorol. Soc., 76, 889-904, doi:10.1175/1520-0477(1995)076<0889:TASTE>2.0.CO;2, 1995.

Arakawa, A. and Lamb, V. R.: Computational design of the basic dynamical process of the UCLA general circulation model, in: Methods in Computational Physics, Vol. 17, Academic Press, New York, 173-265, 1977.

Bates, T. S., Huebert, B. J., Gras, J. L., Griffiths, F. B., and Durkee, P. A.: International Global Atmospheric Chemistry (IGAC) Project's First Aerosol Characterization Experiment (ACE 1): overview, J. Geophys. Res., 103, 16297-16318, doi:10.1029/97JD03741, 1998.

Bellouin, N.: Interaction of UKCA aerosols with radiation: UKCA RADAER, Tech. rep., UK Met Office, available at: http://www. ukca.ac.uk/wiki/images/d/dc/UKCA_RADAER.pdf (last access: April 2014), 2010.

Bellouin, N., Mann, G. W., Woodhouse, M. T., Johnson, C., Carslaw, K. S., and Dalvi, M.: Impact of the modal aerosol scheme GLOMAP-mode on aerosol forcing in the Hadley Centre Global Environmental Model, Atmos. Chem. Phys., 13, 30273044, doi:10.5194/acp-13-3027-2013, 2013.

Boers, R., Jensen, J. B., and Krummel, P. B.: Microphysical and short-wave radiative structure of stratocumulus clouds over the Southern Ocean: summer results and seasonal differences, Q. J. Roy. Meteor. Soc., 124, 151-168, doi:10.1002/qj.49712454507, 1998.

Bogenschutz, P. A., Gettelman, A., Morrison, H., Larson, V. E., Craig, C., and Schanen, D. P.: Higher-Order Turbulence Closure and Its Impact on Climate Simulations in the Community Atmosphere Model, J. Climate, 26, 9655-9676, doi:10.1175/JCLI-D13-00075.1, 2013.
Bretherton, C. S., Wood, R., George, R. C., Leon, D., Allen, G., and Zheng, X.: Southeast Pacific stratocumulus clouds, precipitation and boundary layer structure sampled along $20^{\circ} \mathrm{S}$ during VOCALS-REx, Atmos. Chem. Phys., 10, 10639-10654, doi:10.5194/acp-10-10639-2010, 2010.

Chuang, C. C., Penner, J. E., Taylor, K. E., Grossman, A. S., and Walton, J. J.: An assessment of the radiative effects of anthropogenic sulphate, J. Geophys. Res., 102, 3761-3778, 1997.

Davies, T., Cullen, M. J. P., Malcolm, A. J., Mawson, M. H., Staniforth, A., White, A. A., and Wood, N.: A new dynamical core for the Met Office's global and regional modelling of the atmosphere, Q. J. Roy. Meteor. Soc., 131, 1759-1782, doi:10.1256/qj.04.101, 2005.

Easter, R. C., Ghan, S. J., Zhang, Y., Saylor, R. D., Chapman, E. G., Laulainen, N. S., Abdul-Razzak, H., Leung, L. R., Bian, X., and Zaveri, R. A.: MIRAGE: Model description and evaluation of aerosols and trace gases, J. Geophys. Res., 109, D20210, doi:10.1029/2004JD004571, 2004.

Forster, P., Ramaswamy, V., Artaxo, P., Berntsen, T., Betts, R., Fahey, D. W., Haywood, J., Lean, J., Lowe, D. C., Myhre, G., Nganga, J., Prinn, R., Raga, G., Schulz, M., and Van Dorland, R.: Climate Change 2007: The Scientific Basis. Contribution of working group I to the Fourth Assessment Report of the Intergovernmental Panel on Climate, chap. Radiative Forcing of Climate Change, Cambridge University Press, Cambridge, UK, 129-234, 2007.

Fountoukis, C. and Nenes, A.: Continued development of a cloud droplet formation parameterization for global climate models, J. Geophys. Res., 110, D11212, doi:10.1029/2004JD005591, 2005.

Gettelman, A., Morrison, H., and Ghan, S. J.: A new twomoment bulk stratiform cloud microphysics scheme in the Community Atmosphere Model, Version 3 (CAM3). Part II: single-column and global results, J. Climate, 21, 3660-3679, doi:10.1175/2008JCLI2116.1, 2008.

Ghan, S. J., Leung, R., Easter, R. C., and Abdul-Razzak, H.: Prediction of cloud droplet number in a general circulation model, J. Geophys. Res., 102, 777-794, doi:10.1029/97JD01810, 1997.

Ghan, S., Easter, R., Hudson, J., and Bréon, F.-M.: Evaluation of aerosol indirect radiative forcing in MIRAGE, J. Geophys. Res., 106, 5317-5334, doi:10.1029/2000JD900501, 2001a.

Ghan, S. J., Easter, R. C., Chapman, E. G., Abdul-Razzak, H., Zhang, Y., Leung, R., Laulainen, N. S., Saylor, R. D., and Zaveri, R. A.: A physically based estimate of radiative forcing by anthropogenic sulfate aerosol, J. Geophys. Res., 106, 5279-5293, doi:10.1029/2000JD900503, 2001b.

Ghan, S., Abdul-Razzak, H., Nenes, A., Ming, Y., Liu, X., Ovchinnikov, M., Shipway, B., Meskhidze, N., Xu, J., and Shi, X.: Droplet nucleation: physically-based parameterizations and comparative evaluation, J. Adv. Model. Earth Syst., 3, M10001, doi:10.1029/2011MS000074, 2011.

Ghate, V. P., Albrecht, B. A., and Kollias, P.: Vertical velocity structure of nonprecipitating continental boundary layer stratocumulus clouds, J. Geophys. Res., 115, D13204, doi:10.1029/2009JD013091, 2010.

Golaz, J.-C., Larson, V. E., and Cotton, W. R.: A PDF-based model for boundary layer clouds. Part I: Method and model description, J. Atmos. Sci., 59, 3540-3551, doi:10.1175/15200469(2002)059<3540:APBMFB>2.0.CO;2, 2002. 
Golaz, J.-C., Larson, V. E., Hansen, J. A., Schanen, D. P., and Griffin, B. M.: Elucidating model inadequacies in a cloud parameterization by use of an ensemble-based calibration framework, Mon. Weather Rev., 135, 4077-4096, doi:10.1175/2007MWR2008.1, 2007.

Golaz, J.-C., Salzmann, M., Donner, L. J., Horowitz, L. W., Ming, Y., and Zhao, M.: Sensitivity of the aerosol indirect effect to subgrid variability in the cloud parameterization of the GFDL atmosphere general circulation model AM3, J. Climate, 24, 31453160, doi:10.1175/2010JCLI3945.1, 2011.

Goto, D., Takemura, T., and Nakajima, T.: Importance of global aerosol modeling including secondary organic aerosol formed from monoterpene, J. Geophys. Res., 113, D07205, doi:10.1029/2007JD009019, 2008.

Gregory, D. and Rowntree, P. R.: A mass flux convection scheme with representation of cloud ensemble characteristics and stability-dependent closure, Mon. Weather Rev., 118, 1483-1506, doi:10.1175/15200493(1990)118<1483:AMFCSW>2.0.CO;2, 1990.

Guibert, S., Snider, J. R., and Brenguier, J.-L.: Aerosol activation in marine stratocumulus clouds: 1 . Measurement validation for a closure study, J. Geophys. Res., 108, 8628, doi:10.1029/2002JD002678, 2003.

Gultepe, I. and Isaac, G.: The relationship between cloud droplet and aerosol number concentrations for climate models, Int. J. Climatol., 16, 941-946, 1996.

Guo, H., Golaz, J.-C., Donner, L. J., Larson, V. E., Schanen, D. P., and Griffin, B. M.: Multi-variate probability density functions with dynamics for cloud droplet activation in large-scale models: single column tests, Geosci. Model Dev., 3, 475-486, doi:10.5194/gmd-3-475-2010, 2010.

Guo, H., Golaz, J.-C., Donner, L. J., Ginoux, P., and Hemler, R. S.: Multivariate Probability Density Functions with Dynamics in the GFDL Atmospheric General Circulation Model: Global Tests, J. Climate, 27, 2087-2108, doi:10.1175/JCLI-D-13-00347.1, 2013.

Haywood, J. M., Donner, L. J., Jones, A., and Golaz, J.-C.: Global indirect radiative forcing caused by aerosols: IPCC (2007) and beyond, in: Clouds in the Perturbed Climate System: Their Relationship to Energy Balance, Atmospheric Dynamics, and Precipitation, edited by: Heintzenberg, J. and Charlson, R. J., MIT Press, Cambridge, USA, 451-467, 2009.

Hewitt, H. T., Copsey, D., Culverwell, I. D., Harris, C. M., Hill, R. S. R., Keen, A. B., McLaren, A. J., and Hunke, E. C.: Design and implementation of the infrastructure of HadGEM3: the nextgeneration Met Office climate modelling system, Geosci. Model Dev., 4, 223-253, doi:10.5194/gmd-4-223-2011, 2011.

Hogan, R. J., Grant, A. L. M., Illingworth, A. J., Pearson, G. N., and O'Connor, E. J.: Vertical velocity variance and skewness in clear and cloud-topped boundary layers as revealed by Doppler lidar, Q. J. Roy. Meteor. Soc., 135, 635-643, doi:10.1002/qj.413, 2009.

Hoose, C., Kristjánsson, J. E., Iversen, T., Kirkevåg, A., Seland, O., and Gettelman, A.: Constraining cloud droplet number concentration in GCMs suppresses the aerosol indirect effect, Geophys. Res. Lett., 36, L12807, doi:10.1029/2009GL038568, 2009.

Hoose, C., Kristjánsson, J. E., Arabas, S., Boers, R., Pawlowska, H., Puygrenier, V., Siebert, H., and Thouron, O.: Parameterization of in-cloud vertical velocities for cloud droplet activation in coarsegrid models: analysis of observations and cloud resolving model results, in: AMS Cloud Physics Conference, available at: https: //ams.confex.com/ams/pdfpapers/170866.pdf (last access: April 2014), 2010.

Hudson, J. G., Xie, Y., and Yum, S. S.: Vertical distributions of cloud condensation nuclei spectra over the summertime Southern Ocean, J. Geophys. Res., 103, 16609-16624, doi:10.1029/97JD03438, 1998.

Jones, A., Roberts, D. L., Woodage, M. J., and Johnson, C. E.: Indirect sulphate aerosol forcing in a climate model with an interactive sulphur cycle, J. Geophys. Res., 106, 20293-20310, doi:10.1029/2000JD000089, 2001.

Kipling, Z., Stier, P., Schwarz, J. P., Perring, A. E., Spackman, J. R., Mann, G. W., Johnson, C. E., and Telford, P. J.: Constraints on aerosol processes in climate models from vertically-resolved aircraft observations of black carbon, Atmos. Chem. Phys., 13, 5969-5986, doi:10.5194/acp-13-5969-2013, 2013.

Köhler, H.: The nucleus in and the growth of hygroscopic droplets and the growth of hygroscopic droplets, T. Faraday Soc., 32, 1152-1161, 1936.

Lamarque, J.-F., Bond, T. C., Eyring, V., Granier, C., Heil, A., Klimont, Z., Lee, D., Liousse, C., Mieville, A., Owen, B., Schultz, M. G., Shindell, D., Smith, S. J., Stehfest, E., Van Aardenne, J., Cooper, O. R., Kainuma, M., Mahowald, N., McConnell, J. R., Naik, V., Riahi, K., and van Vuuren, D. P.: Historical (1850-2000) gridded anthropogenic and biomass burning emissions of reactive gases and aerosols: methodology and application, Atmos. Chem. Phys., 10, 7017-7039, doi:10.5194/acp10-7017-2010, 2010.

Larson, V. E., Golaz, J.-C., and Cotton, W. R.: Small-scale and mesoscale variability in cloudy boundary layers: joint probability density functions, J. Atmos. Sci., 59, 3519-3539, doi:10.1175/1520-0469(2002)059<3519:SSAMVI>2.0.CO;2, 2002.

Leaitch, W. R., Banic, C. M., Isaac, G. A., Couture, M. D., Liu, P. S. K., Gultepe, I., Li, S.-M., Kleinman, L., Daum, P. H., and MacPherson, J. I.: Physical and chemical observations in marine stratus during the 1993 North Atlantic Regional Experiment: factors controlling cloud droplet number concentrations, J. Geophys. Res., 101, 29123-29135, doi:10.1029/96JD01228, 1996.

Lee, L. A., Pringle, K. J., Reddington, C. L., Mann, G. W., Stier, P., Spracklen, D. V., Pierce, J. R., and Carslaw, K. S.: The magnitude and causes of uncertainty in global model simulations of cloud condensation nuclei, Atmos. Chem. Phys., 13, 8879-8914, doi:10.5194/acp-13-8879-2013, 2013.

Lock, A. P.: The parametrization of entrainment in cloudy boundary layers, Q. J. Roy. Meteor. Soc., 124, 2729-2753, doi:10.1002/qj.49712455210, 1998.

Lock, A. P. and Edwards, J.: UMDP24: the parametrization of boundary layer processes, Tech. Rep. 24, Met Office, Exeter, UK, 2011.

Lock, A. P., Brown, A. R., Bush, M. R., Martin, G. M., and Smith, R. N. B.: A new boundary layer mixing scheme. Part I: scheme description and single-column model tests, Mon. Weather Rev., 128, 3187-3199, doi:10.1175/15200493(2000)128<3187:ANBLMS>2.0.CO;2, 2000.

Lohmann, U.: Possible aerosol effects on ice clouds via contact nucleation, J. Atmos. Sci., 59, 647-656, doi:10.1175/15200469(2001)059<0647:PAEOIC>2.0.CO;2, 2002. 
Lohmann, U., Feichter, J., Chuang, C. C., and Penner, J. E.: Prediction of the number of cloud droplets in the ECHAM GCM, J. Geophys. Res., 104, 9169-9198, doi:10.1029/1999JD900046, 1999.

Lohmann, U., Rotstayn, L., Storelvmo, T., Jones, A., Menon, S., Quaas, J., Ekman, A. M. L., Koch, D., and Ruedy, R.: Total aerosol effect: radiative forcing or radiative flux perturbation?, Atmos. Chem. Phys., 10, 3235-3246, doi:10.5194/acp-10-32352010, 2010.

Lu, M.-L., Conant, W. C., Jonsson, H. H., Varutbangkul, V., Flagan, R. C., and Seinfeld, J. H.: The Marine Stratus/Stratocumulus Experiment (MASE): Aerosol-cloud relationships in marine stratocumulus, J. Geophys. Res., 112, D10209, doi:10.1029/2006JD007985, 2007.

Lu, M.-L., Sorooshian, A., Jonsson, H. H., Feingold, G., Flagan, R. C., and Seinfeld, J. H.: Marine stratocumulus aerosol-cloud relationships in the MASE-II experiment: precipitation susceptibility in eastern Pacific marine stratocumulus, J. Geophys. Res., 114, D24203, doi:10.1029/2009JD012774, 2009.

Mann, G. W., Carslaw, K. S., Spracklen, D. V., Ridley, D. A., Manktelow, P. T., Chipperfield, M. P., Pickering, S. J., and Johnson, C. E.: Description and evaluation of GLOMAP-mode: a modal global aerosol microphysics model for the UKCA composition-climate model, Geosci. Model Dev., 3, 519-551, doi:10.5194/gmd-3-519-2010, 2010.

Mann, G. W., Carslaw, K. S., Ridley, D. A., Spracklen, D. V., Pringle, K. J., Merikanto, J., Korhonen, H., Schwarz, J. P., Lee, L. A., Manktelow, P. T., Woodhouse, M. T., Schmidt, A., Breider, T. J., Emmerson, K. M., Reddington, C. L., Chipperfield, M. P., and Pickering, S. J.: Intercomparison of modal and sectional aerosol microphysics representations within the same 3-D global chemical transport model, Atmos. Chem. Phys., 12, 4449-4476, doi:10.5194/acp-12-4449-2012, 2012.

Martin, G. M., Johnson, D. W., and Spice, A.: The measurement and parameterization of effective radius of droplets in warm stratiform clouds, J. Atmos. Sci., 51, 1823-1842, 1994.

Meskhidze, N., Nenes, A., Conant, W. C., and Seinfeld, J. H.: Evaluation of a new cloud droplet activation parameterization with in situ data from CRYSTAL-FACE and CSTRIPE, J. Geophys. Res., 110, D16202, doi:10.1029/2004JD005703, 2005.

Ming, Y., Ramaswamy, V., Donner, L. J., and Phillips, V. T. J.: A new parameterization of cloud droplet activation applicable to general circulation models, J. Atmos. Sci., 63, 1348-1356, doi:10.1175/JAS3686.1, 2006.

Ming, Y., Ramaswamy, V., Donner, L. J., Phillips, V. T. J., Klein, S. A., Ginoux, P. A., and Horowitz, L. W.: Modeling the interactions between aerosols and liquid water clouds with a selfconsistent cloud scheme in a general circulation model, J. Atmos. Sci., 64, 1189-1209, doi:10.1175/JAS3874.1, 2007.

Morales, R. and Nenes, A.: Characteristic updrafts for computing distribution-averaged cloud droplet number and stratocumulus cloud properties, J. Geophys. Res., 115, D18220, doi:10.1029/2009JD013233, 2010.

Morgenstern, O., Braesicke, P., O’Connor, F. M., Bushell, A. C., Johnson, C. E., Osprey, S. M., and Pyle, J. A.: Evaluation of the new UKCA climate-composition model - Part 1: The stratosphere, Geosci. Model Dev., 2, 43-57, doi:10.5194/gmd-2-432009, 2009.
Morrison, H. and Gettelman, A.: A new two-moment bulk stratiform cloud microphysics scheme in the Community Atmosphere Model, Version 3 (CAM3). Part I: description and numerical tests, J. Climate, 21, 3642-3659, doi:10.1175/2008JCLI2105.1, 2008.

Moyer, K. A. and Young, G. S.: Observations of vertical velocity skewness within the marine stratocumulus-topped boundary layer, J. Atmos. Sci., 48, 403-410, doi:10.1175/15200469(1991)048<0403:OOVVSW>2.0.CO;2, 1991.

Nenes, A. and Seinfeld, J. H.: Parameterization of cloud droplet formation in global climate models, J. Geophys. Res., 108, 4415, doi:10.1029/2002JD002911, 2003.

O'Connor, F. M., Johnson, C. E., Morgenstern, O., Abraham, N. L., Braesicke, P., Dalvi, M., Folberth, G. A., Sanderson, M. G., Telford, P. J., Voulgarakis, A., Young, P. J., Zeng, G., Collins, W. J., and Pyle, J. A.: Evaluation of the new UKCA climatecomposition model - Part 2: The Troposphere, Geosci. Model Dev., 7, 41-91, doi:10.5194/gmd-7-41-2014, 2014.

Partridge, D. G., Vrugt, J. A., Tunved, P., Ekman, A. M. L., Struthers, H., and Sorooshian, A.: Inverse modelling of cloudaerosol interactions - Part 2: Sensitivity tests on liquid phase clouds using a Markov chain Monte Carlo based simulation approach, Atmos. Chem. Phys., 12, 2823-2847, doi:10.5194/acp12-2823-2012, 2012.

Pawlowska, H. and Brenguier, J. L.: Microphysical properties of stratocumulus clouds during ACE-2, Tellus B, 52, 868-887, doi:10.1034/j.1600-0889.2000.00076.x, 2000.

Peng, Y., Lohmann, U., and Leaitch, R.: Importance of vertical velocity variations in the cloud droplet nucleation process of marine stratus clouds, J. Geophys. Res., 110, D21213, doi:10.1029/2004JD004922, 2005.

Quaas, J., Ming, Y., Menon, S., Takemura, T., Wang, M., Penner, J. E., Gettelman, A., Lohmann, U., Bellouin, N., Boucher, O., Sayer, A. M., Thomas, G. E., McComiskey, A., Feingold, G., Hoose, C., Kristjánsson, J. E., Liu, X., Balkanski, Y., Donner, L. J., Ginoux, P. A., Stier, P., Grandey, B., Feichter, J., Sednev, I., Bauer, S. E., Koch, D., Grainger, R. G., Kirkevåg, A., Iversen, T., Seland, Ø., Easter, R., Ghan, S. J., Rasch, P. J., Morrison, H., Lamarque, J.-F., Iacono, M. J., Kinne, S., and Schulz, M.: Aerosol indirect effects - general circulation model intercomparison and evaluation with satellite data, Atmos. Chem. Phys., 9, 8697-8717, doi:10.5194/acp-9-8697-2009, 2009.

Reddington, C. L., McMeeking, G., Mann, G. W., Coe, H., Frontoso, M. G., Liu, D., Flynn, M., Spracklen, D. V., and Carslaw, K. S.: The mass and number size distributions of black carbon aerosol over Europe, Atmos. Chem. Phys., 13, 4917-4939, doi:10.5194/acp-13-4917-2013, 2013.

Reutter, P., Su, H., Trentmann, J., Simmel, M., Rose, D., Gunthe, S. S., Wernli, H., Andreae, M. O., and Pöschl, U.: Aerosol- and updraft-limited regimes of cloud droplet formation: influence of particle number, size and hygroscopicity on the activation of cloud condensation nuclei (CCN), Atmos. Chem. Phys., 9, 70677080, doi:10.5194/acp-9-7067-2009, 2009.

Romakkaniemi, S., McFiggans, G., Bower, K. N., Brown, P., Coe, H., and Choularton, T. W.: A comparison between trajectory ensemble and adiabatic parcel modeled cloud properties and evaluation against airborne measurements, J. Geophys. Res., 114, D06214, doi:10.1029/2008JD011286, 2009. 
Rotstayn, L. D. and Penner, J. E.: Indirect aerosol forcing, quasiforcing and climate response, J. Climate, 14, 2960-2975, 2001.

Shipway, B. and Abel, S.: Analytical estimation of cloud droplet nucleation based on an underlying aerosol population, Atmos. Res., 96, 344-355, doi:10.1016/j.atmosres.2009.10.005, 2010.

Spracklen, D. V.: Development and application of a Glomap Model of Aerosol Processes (GLOMAP), Ph.D. thesis, University of Leeds, Leeds, UK, 2005.

Spracklen, D. V., Carslaw, K. S., Kulmala, M., Kerminen, V.-M., Sihto, S.-L., Riipinen, I., Merikanto, J., Mann, G. W., Chipperfield, M. P., Wiedensohler, A., Birmili, W., and Lihavainen, H.: Contribution of particle formation to global cloud condensation nuclei concentrations, Geophys. Res. Lett., 35, L06808, doi:10.1029/2007GL033038, 2008.

Spracklen, D. V., Carslaw, K. S., Pöschl, U., Rap, A., and Forster, P. M.: Global cloud condensation nuclei influenced by carbonaceous combustion aerosol, Atmos. Chem. Phys., 11, 9067-9087, doi:10.5194/acp-11-9067-2011, 2011.

Storelvmo, T., Kristjánsson, J. E., Ghan, S. J., Kirkevåg, A., Seland, O., and Iversen, T.: Predicting cloud droplet number concentration in Community Atmosphere Model (CAM)-Oslo, J. Geophys. Res., 111, D24208, doi:10.1029/2005JD006300, 2006.

Takemura, T., Nozawa, T., Emori, S., Nakajima, T. Y., and Nakajima, T.: Simulation of climate response to aerosol direct and indirect effects with aerosol transport-radiation model, J. Geophys. Res., 110, D02202, doi:10.1029/2004JD005029, 2005.

Telford, P. J., Braesicke, P., Morgenstern, O., and Pyle, J. A.: Technical Note: Description and assessment of a nudged version of the new dynamics Unified Model, Atmos. Chem. Phys., 8, 17011712, doi:10.5194/acp-8-1701-2008, 2008.

Telford, P. J., Lathière, J., Abraham, N. L., Archibald, A. T., Braesicke, P., Johnson, C. E., Morgenstern, O., O’Connor, F. M., Pike, R. C., Wild, O., Young, P. J., Beerling, D. J., Hewitt, C. N., and Pyle, J.: Effects of climate-induced changes in isoprene emissions after the eruption of Mount Pinatubo, Atmos. Chem. Phys., 10, 7117-7125, doi:10.5194/acp-10-7117-2010, 2010.

Telford, P. J., Abraham, N. L., Archibald, A. T., Braesicke, P., Dalvi, M., Morgenstern, O., O'Connor, F. M., Richards, N. A. D., and Pyle, J. A.: Implementation of the Fast-JX Photolysis scheme (v6.4) into the UKCA component of the MetUM chemistry-climate model (v7.3), Geosci. Model Dev., 6, 161177, doi:10.5194/gmd-6-161-2013, 2013.
Tripoli, G. J. and Cotton, W. R.: A numerical investigation of several factors contributing to the observed variable intensity of deep convection of South Florida, J. Appl. Meteorol., 19, 1037-1063, 1980.

Tunved, P., Partridge, D. G., and Korhonen, H.: New trajectorydriven aerosol and chemical process model Chemical and Aerosol Lagrangian Model (CALM), Atmos. Chem. Phys., 10, 10161-10185, doi:10.5194/acp-10-10161-2010, 2010.

Twomey, S.: The nuclei of natural cloud formation, Part II: The supersaturation in natural clouds and the variation of cloud droplet concentration, Geofis. Pura Appl., 43, 243-249, 1959.

Vignati, E., Wilson, J., and Stier, P.: M7: An efficient size-resolved aerosol microphysics module for large-scale aerosol transport models, J. Geophys. Res., 109, D22202, doi:10.1029/2003JD004485, 2004.

Wang, M. and Penner, J. E.: Aerosol indirect forcing in a global model with particle nucleation, Atmos. Chem. Phys., 9, 239-260, doi:10.5194/acp-9-239-2009, 2009.

Wilson, D. R., Bushell, A. C., Kerr-Munslow, A. M., Price, J. D., and Morcrette, C. J.: PC2: a prognostic cloud fraction and condensation scheme. I: Scheme description, Q. J. Roy. Meteor. Soc., 134, 2093-2107, doi:10.1002/qj.333, 2008.

Woodward, S.: Modeling the atmospheric life cycle and radiative impact of mineral dust in the Hadley Centre climate model, J. Geophys. Res., 106, 18155-18166, doi:10.1029/2000JD900795, 2001.

Yum, S. S., Hudson, J. G., and Xie, Y.: Comparisons of cloud microphysics with cloud condensation nuclei spectra over the summertime Southern Ocean, J. Geophys. Res., 103, 16625-16636, doi:10.1029/98JD01513, 1998.

Zhu, P. and Zuidema, P.: On the use of PDF schemes to parameterize sub-grid clouds, Geophys. Res. Lett., 36, L05807, doi:10.1029/2008GL036817, 2009.

Zhu, P., Albrecht, B. A., Ghate, V. P., and Zhu, Z.: Multiplescale simulations of stratocumulus clouds, J. Geophys. Res., 115 D23201, doi:10.1029/2010JD014400, 2010. 